\title{
Antimicrobial Resistance Patterns and Molecular Characterization of Klebsiella pneumoniae in Clinical Isolates at Mbarara Regional Referral Hospital
}

\author{
Joseph Turugurwa ${ }^{1 *}$, James Mwesigye ${ }^{1}$, Kennedy Kassaza ${ }^{1}$, Fredrick Byarugaba ${ }^{1}$, \\ Taseera Kabanda ${ }^{1}$, Benson Musinguzi ${ }^{2 *}$
}

${ }^{1}$ Department of Microbiology, Faculty of Medicine, Mbarara University of Science and Technology, Mbarara, Uganda

${ }^{2}$ Department of Medical Laboratory Sciences, School of Allied Health Sciences, Kampala International University, Bushenyi, Uganda

Email: *turugurwaandjoseph@gmail.com

How to cite this paper: Turugurwa, J., Mwesigye, J., Kassaza, K., Byarugaba, F., Kabanda, T. and Musinguzi, B. (2019) Antimicrobial Resistance Patterns and Molecular Characterization of Klebsiella pneumoniae in Clinical Isolates at Mbarara Regional Referral Hospital. Advances in Infectious Diseases, 9, 197-225.

https://doi.org/10.4236/aid.2019.93015

Received: June 27, 2019

Accepted: July 29, 2019

Published: August 1, 2019

Copyright $\odot 2019$ by author(s) and Scientific Research Publishing Inc. This work is licensed under the Creative Commons Attribution International License (CC BY 4.0).

http://creativecommons.org/licenses/by/4.0/

\begin{abstract}
Background: Klebsiella pneumoniae is one of the most frequent opportunistic pathogens causing a range of infections and being resistant for beta-lactamases (ESBL) and Carbapenemases. Aim: The aim of the present study was to determine the antimicrobial resistance patterns and molecular characterization establishing the phenotypes and genotypes associated with drug resistance, an antibiogram of genotypically positive isolates for resistance of Klebsiella pneumoniae in clinical isolates at MRRH. Materials and Methods: A laboratory-based descriptive cross-sectional study that was conducted from September 2018 to May 2019 at MRRH. Klebsiella pneumoniae was identified by cultural and biochemical methods. Antibiotic sensitivity test was performed by modified Kirby-Bauer disc diffusion technique. ESBL production in Klebsiella pneumoniae was tested by double-disc synergy test, Carbapenemase production by MHT, Boronic Acid or EDTA test using Meropenem phenotypically and both resistance confirmed genotypically by Multiplex PCR. Results: Out of 1055 clinical isolates, 298 (28.2\%) were found positive for Klebsiella.spp, 175 isolates were subcultured among which 22 (12.57\%) were K. pneumoniae based on API 20E. Overall Sensitivity patterns of these Klebsiella pneumoniae isolates to Ceftriaxone, (Amoxicillin/Clavulanate), Gentamicin, Cefepime, Ciprofloxacin, Cefoxitin, Nitrofurantoin, Cefuroxime, piperacillin/tazobactam, Meropenem, Ceftazidime and cefotaxime were $72.7 \%$, 63.7\%, 54.5\%, 45.5\%, 31.8\%, 31.8\%, 27.3\%, 27.3\%, 22.7\%, 22.7\%, 18.2\%, 9.1\%, 9.1\% respectively. ESBL producing $K$. pneumoniae was found at $68.18 \%$ (15/22) phenotypically. Genotypically; the ESBL genes were $b^{1} a_{\text {CTX-M }}(100 \%)$,
\end{abstract}


$b l a_{\mathrm{SHV}}(80 \%)$ and $b a_{\mathrm{TEM}}(100 ; 47 \%) ; 8 / 15(73.3 \%)$ had CTX-M, SHV, TEM, 4/15 (26.67\%) CTX-M, TEM, $3 / 15$ (20.00\%) CTX-M and SHV. Carbapenemase producing $K$. pneumoniae was found at $31.82 \%$ (7/22) phenotypically; $1 / 7$ (14.28\%) by MHT, 4/7 (57.14\%) Boronic acid test and 2/7 (28.58\%) EDTA test. Genotypically; 3/4 [(75\%) 42.86\%] had OXA-48, 1/4 [(25\%) 14.28\%] OXA-48 and KPC gene, 1/2 [(50\%) 14.28\%] KPC and VIM, 1/2 [(50\%) 14.28\%] KPC and KPC gene [(100\%) 14.28\%]. Conclusion/Recommendations: DDS to be used for ESBL production, MHT, Boronic Acid test and EDTA tests using Meropenem/or Imipenem for Carbapenemase-production routinely.

\section{Keywords}

Antimicrobial Resistance Patterns, ESBLs, Carbapenemase Resistance, Klebsiella pneumoniae

\section{Introduction}

\section{Background}

Klebsiella pneumoniae has traditionally been considered an opportunistic pathogen and is a common cause of nosocomial infections ranking second to $E$. coli but recently has surpassed Escherichia coli as the most common cause of liver abscess [1] since its discovery in 1883 by Carl Friedländer, a German pathologist [2] later given a generic name of Klebsiella after the German bacteriologist Edwin Klebs [3]. Its Gram-negative bacillus of the Enterobacteriaceae family, non-motile, encapsulated, lactose-fermenting, facultatively anaerobic, rodshaped bacterium measuring $2 \mu \mathrm{m}$ by $0.5 \mu \mathrm{m}$ and appears as a mucoid lactose fermenter on MacConkey agar [4].

The presence of a capsule around its cell known as $\mathrm{K}$ antigen is a reason for its pathogenicity, which protects the bacteria from phagocytosis during the course of infection [5]. There are 77 different capsular $(K)$ antigens denoted from $K_{1}$ through up to $\mathrm{K}_{77}$, and certain serotypes are associated with certain infection sites [6]. Its infections are mostly seen in immunocompromised individuals thus grouped as opportunistic pathogen, seen mostly affecting middle-aged and older men with debilitating diseases [2]. This patient population is believed to have impaired respiratory host defenses, including persons with diabetes, alcoholism, malignancy, liver disease, chronic obstructive pulmonary diseases, glucocorticoid therapy and renal failure [7].

A new antibiotic-resistant strain of $K$. pneumonia [8] is responsible for serious disseminated infections, such as pyogenic liver abscesses, osteomyelitis, and endophthalmitis, in a generally younger and healthier population [9]. It has a range of clinical diseases which include pneumonia, thrombophlebitis, urinary tract infection, cholecystitis, diarrhea, upper respiratory tract infection, wound infection, meningitis, bacteremia and septicemia [10] with a mortality rate of $50 \%$ which can be nearly $100 \%$ for people with alcoholism and bacteremia, even 
with antimicrobial therapy [11].

Resistance is attributed to plasmids as a source of the resistant genes [12] and can be categorized based on of prevalence of antimicrobial resistance genes as extended-spectrum $\beta$-lactamase (ESBLs) [13], plasmid-mediated quinolone resistance (PMQR) genes [14] especially involving Qnr proteins and the aminoglycoside acetyltransferase variant determinant (AAC(6')-Ib-cr), which has emerged and is now described worldwide [15] and 16S rRNA methylase (16S-RMTase) genes [16].

The ability to produce ESBLs, Klebsiella pneumoniae has become resistant to beta-lactam antibiotics [17] including fluoroquinolones, aminoglycosides, trimethoprim, and sulphamethoxazole [16] thus related infections have caused high rates of morbidity and mortality, particularly among persons with prolonged hospitalization and those critically ill and exposed to invasive devices (ventilators or central venous catheters).

Carbapenems over years have been the last line drugs for the Klebsiella pneumoniae related infections but carbapenem-resistant Klebsiella pneumoniae (CRKP) have emerged [18] arising from; hyperproduction of ampC beta-lactamase with an outer membrane porin mutation, CTX-M extended-spectrum beta-lactamase with a porin mutation or drug efflux, and carbapenemase enzyme production, where blakpc gene that encodes for it is carried on a mobile piece of genetic material (a transposon; the specific transposon involved is called Tn4401), which increases the risk for dissemination [19]. Strains that harbor blakpc have minimum inhibitory concentrations within the susceptible range for carbapenems thus patients with unrecognized CRKP colonization have become reservoirs for transmission during nosocomial outbreaks [17].

The mode of transmission is through person-to-person contact (contaminated hands of healthcare personnel, or other people via patient to patient); Patients with an invasive device in their bodies (neonatal ward devices, respiratory support equipment in ICUs, cannulars and urinary catheters) put patients at increased risk [20]. Prevention follows specific infection-control precautions, which include strict adherence to hand hygiene (preferably using an alcoholbased hand rub (60-90\%) or soap and water if hands are visibly soiled [21]. Alcohol based hand rubs, wearing gowns and gloves when entering rooms where patients with Klebsiella-related illnesses are housed, are effective against these Gram-negative bacilli [22]. Healthcare facilities also must follow strict cleaning procedures to prevent the spread of Klebsiella pneumoniae [23].

Treatment for $K$. pneumoniae infections is difficult because of the emerging resistance to traditional antibiotics which used to be effective against them thus tests to determine which antibiotics will treat this infection is a requirement because the recommended treatment changes as the organism develop resistances [12]. The choice of a specific antimicrobial agent or agents depends on local susceptibility patterns and on the part of the body infected. For patients with severe infections, a best approach is the use of an initial short course (48 - $72 \mathrm{~h}$ ) of 
combination therapy, followed by a switch to a specific monotherapy once the susceptibility pattern is known for the specific patient [24].

\section{Methodology}

\subsection{Study Design}

This was a laboratory-based descriptive cross-sectional study that was conducted from September 2018 to April 2019 in which antimicrobial susceptibility testing and molecular characterization were performed for identified $K$. pneumoniae from clinical isolates.

\subsection{Study Site and Setting}

The study was conducted in the Microbiology Laboratory, Department of Microbiology, Mbarara University of Science and Technology (MUST) whose clinical Microbiology Laboratory serves for Mbarara Regional Referral Hospital (MRRH) for Antimicrobial susceptibility testing and phenotyping for resistance.

Molecular characterization for positive phenotypic isolates for antibiotic resistance was carried out at Inqaba Biotechnical Industries (Pty) Ltd, 525 Justice Mahomed Street, Muckleneuk, Pretoria 0002 South Africa which offers sequencing and primer synthesis services.

\subsection{Sample Size Calculation}

The sample size was computed using the formula:

$$
n=Z^{2} p(1-p) / d^{2} \quad[25]
$$

where:

$$
\begin{aligned}
& n=\text { sample size } \\
& z=\text { statistic for level of confidence } \\
& p=\text { estimated prevalence } \\
& d=\text { precision }
\end{aligned}
$$

Where about $13 \%$ estimated prevalence $(p)$ for Klebsiella spp in a study done in Southwestern Uganda was used [26], precision $(d=0.05)$ and $95 \%$ level of confidence $(z=1.96)$, a $10 \%$ contingency was added to the calculated sample size giving an estimated sample size of 192 .

\subsection{Study Population}

The study population comprised of 175 clinical isolates with Klebsiella like characteristics on growth which were collected from September 2018 to April 2019 from clinical specimens at Microbiology Laboratory at MUST/MRRH. These isolates were from urine (58), sputum (32), pus swabs (26), HVS (23), blood (9), ear swabs (6), pus, pleural fluid ( 3 each), aspirates, CSF, pus aspirates, tracheal aspirates and tracheal swabs (2 each), ascetic fluid, chest pus, peritoneal fluid, posto auricle abscess, stool, throat swab and tracheal tube (1 each) all clinical specimens reaching the Microbiology laboratory at MRRH. 


\subsection{Selection Criteria}

\subsubsection{Inclusion Criteria}

The study included all Klebsiella like isolates from clinical samples (blood culture, urine, stool, peritoneal fluid, pus swab, high vaginal swab, cerebrospinal fluid, pleural fluid/aspirate, sputum, urethral and nasal swabs) collected from in patients and out patients attending Mbarara Regional Referral Hospital between January and May 2019.

\subsubsection{Exclusion Criteria}

The study excluded all duplicated isolates from the same patient unless they were isolated from different specimens with a distinguishable susceptibility pattern.

\subsection{Sample Collection and Handling}

Colonies suggestive of Klebsiella spp on growth (i.e. Colonies typically appearing large, Mucoid and red with red pigment usually diffusing into the surrounding agar, indicating fermentation of lactose and acid production) were picked and emulsified into $1 \mathrm{ml}$ of Brain Heart Infusion (BHI) with $20 \%$ Glycerol later archived at $-20^{\circ} \mathrm{C}$ in a triple series.

\subsection{Cultures}

Isolation of Klebsiella pneumoniae, biochemical testing and the antimicrobial susceptibility testing was performed at the Clinical Microbiology Laboratory, Faculty of Medicine, Mbarara University of Science and Technology (MUST).

One hundred and seventy five Klebsiella spp isolates from different clinical specimens (blood, sputum, urine, pus aspirates and endotracheal secretions) were collected over five months period at MRRH. Specimens reaching the laboratory were cultured on blood agar (Global Scientific Supplies LTD, plot 1495, Roche Close) and MacConkey agar (Mast Group Ltd., Mast House, Derby Road, Bootle, Liverpool, Merseyside, U.K) except for urine samples which were plated on Cysteine Lactose Electrolytes Deficient (CLED) agar (SIGMA-ALDRICH, Co., 3050 Spruce Street, St. Louis, MO 63103 USA 314-771-5765) (Figure 1). All isolated Klebsiella spp strains were identified in the clinical samples by conventional microbiological methods (colonial morphology, Gram staining, and biochemical tests).

\subsection{Biochemical Characterization}

All clinical isolates exhibiting mucoid colonies were processed for biochemical testing. Biochemical test employed were urease production, citrate utilization and fermentation of sugars. Sugar fermentation tests performed were sucrose, glucose, mannitol, lactose, Adonitol, dulcitol, Melibiose and Esculin (using API $20 \mathrm{E}$ ) which are attributable to the majority of $K$. pneumoniae sub species pneu moniae strain, being positive to Adonitol, Melibiose, Esculin, urease and citrate. Indole test and H2S production on TSI agar, oxidase, catalase and nitrate plus 
motility were also carried out [5] following standard procedures (Appendix II omitted as it is not indicated in the manuscript). The isolates were confirmed for K.pneum.pneumoniae (22 Isolates) on API 20E (BioMerieux SA France 69280 Marcy, mini API) with profiles: 521(3)5773, percentage identification (\%id) 97.7 for isolates 5235773, id\% 97.7 (Figure 2).

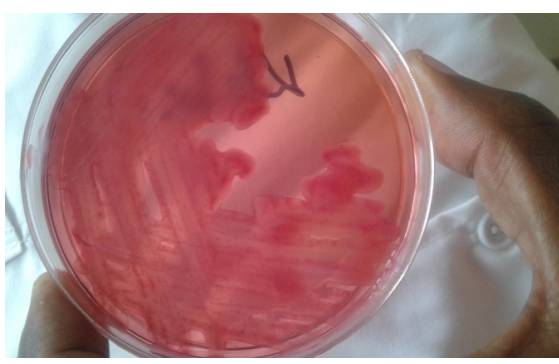

(a)

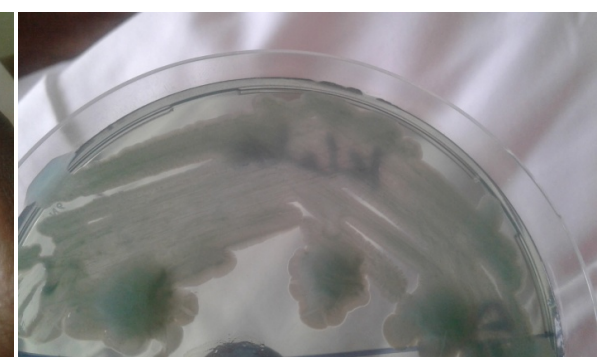

(b)

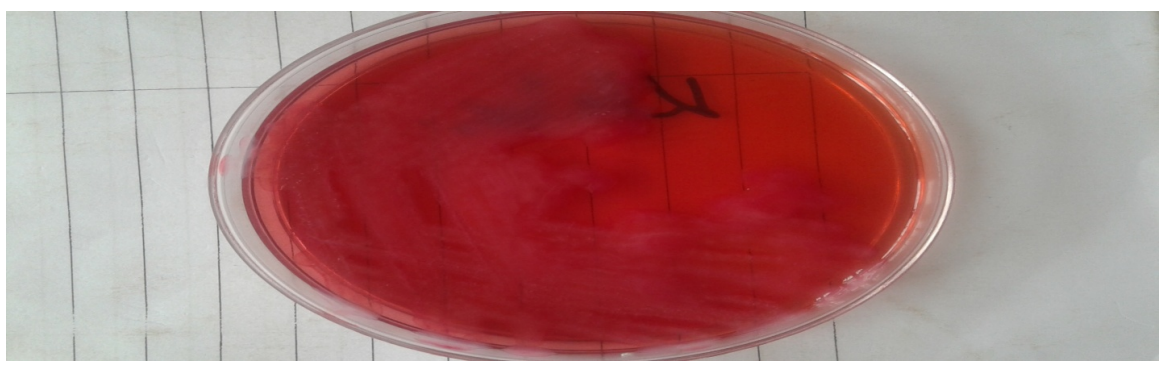

(c)

Figure 1. Mucoid colonies as seen on (a) MCA, (b) CLED, (c) BA.

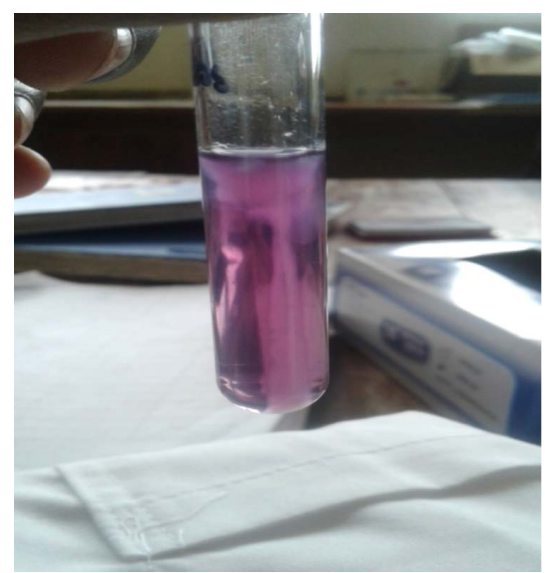

(a)

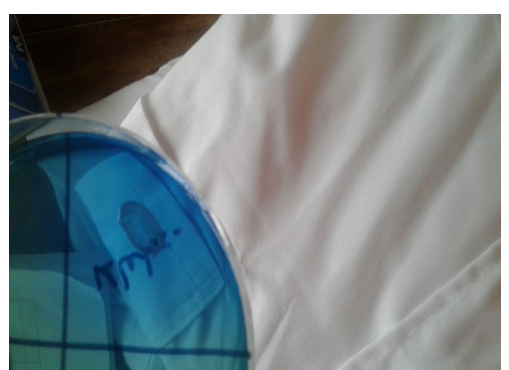

(c)

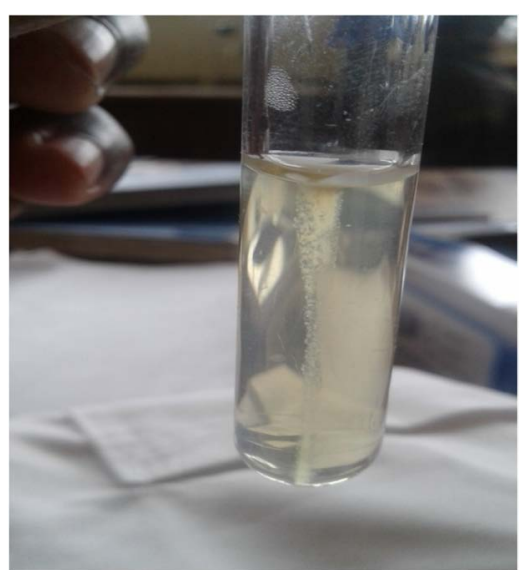

(b)

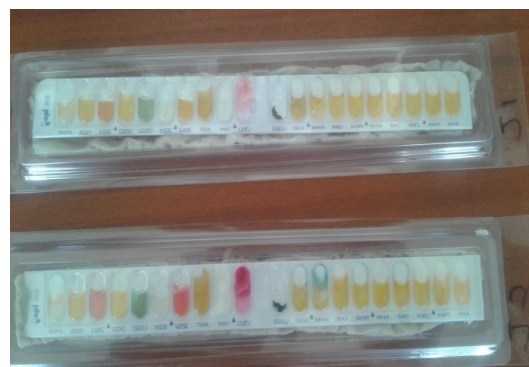

(d) 


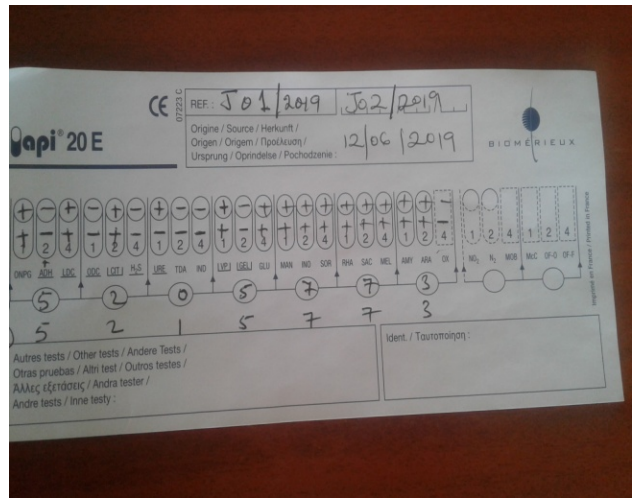

(e)

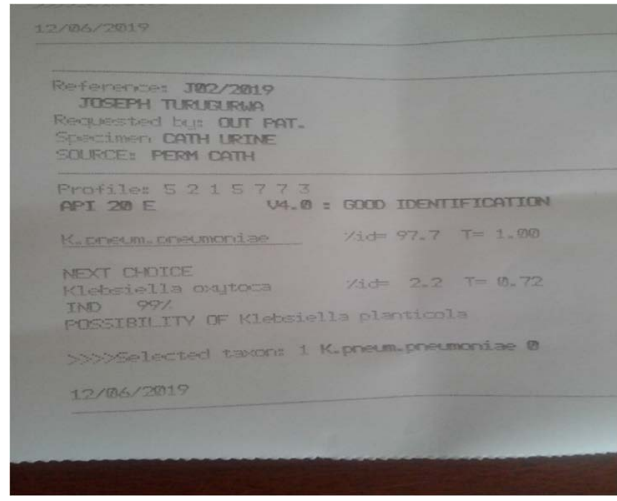

(g)

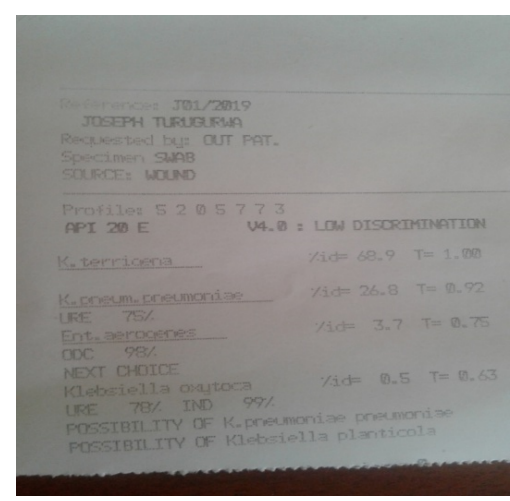

(f)

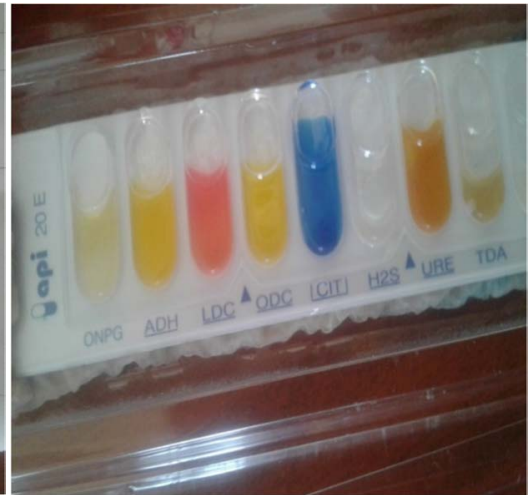

(h)

Figure 2. Biochemical tests for confirmation of $K$. pneumoniae sub species pneumoniae strain; (a) MIO (Motility, Indole, Ornithine), (b) SMI (Sulphite, Motility, Indole), (c) Citrate Utilization on Simmon's Citrate Agar (SCA), (d) API 20E following $24 \mathrm{hr}$ incubation at $37^{\circ} \mathrm{C}$, addition of reagents $\mathrm{VP}_{1,2}$, James reagent and TDA, (e) API 20E leaflet for reading tests, ((f) and (g)) results from mini API machine and (h) API 20E strip after adding $\mathrm{KOH}$ onto CIT well.

\subsection{Antibiotic Sensitivity}

Isolates were tested for the pattern of antimicrobial susceptibilities by an agar disc diffusion method using paper discs (Carramore international limited, Oxoid Ltd, Wade Road, Basingstoke, Hants, RG24 8PW, UK) on Mueller-Hinton (MH) agar including susceptibility to the following antibiotics: amoxicillin/clavulanate $(20 / 10 \mu \mathrm{g})$, cefuroxime $(30 \mu \mathrm{g})$, ceftriaxone $(30 \mu \mathrm{g})$, cefotaxime $(30 \mu \mathrm{g})$, ceftazidime $(30 \mu \mathrm{g})$, meropenem $(30 \mu \mathrm{g})$, gentamicin $(10 \mu \mathrm{g})$, ciprofloxacin $(5 \mu \mathrm{g})$, nitrofurantoin $(300 \mu \mathrm{g})$, cefepime $(30 \mu \mathrm{g})$, piperacillin/tazobactam $(100 / 10 \mu \mathrm{g})$ and cefoxitin $(30 \mu \mathrm{g})$. Organisms were grown in BHI broth, the turbidity of the suspension adjusted to the $0.5 \mathrm{McF}$ arland standard. After overnight incubation at $37^{\circ} \mathrm{C}$, inhibition zone diameters were read (Figure 3 ). The results of a disc diffusion test are interpreted by comparing the measured zone diameter with the interpretive criteria recommended by CLSI guidelines [27].

\subsection{Quality Control and Data Quality Assurance}

Standard operating procedures (SOPs) were strictly followed verifying that me- 
dia meet expiration date and quality control parameters per CLSI 2017. Visual inspections of cracks in media or plastic petridishes, unequal fill, hemolysis, evidence of freezing, bubbles, and contaminations were done. Quality control was performed to check the quality of medium. Each new lot was quality-controlled before use by testing the E. coli ATCC 25922 standard control strain. During ESBLs detection, ESBL-positive Klebsiella pneumoniae ATCC 700603 and ESBL-negative E. coli ATCC 25922 control strains were used in this study. For carbapenemase detection, E. coli ATCC 25922 strain was used as a negative control. Culture results were recorded carefully before data entry, and the data were double-checked by a different person before analysis.

\subsection{Detection of ESBLs}

\subsubsection{Double Disc Synergy Test}

The organism to be tested was spread onto a Mueller-Hinton agar plate. The antibiotic discs used were Ceftriaxone (30 $\mu \mathrm{g})$, Cefotaxime (30 $\mu \mathrm{g})$, Ceftazidime (30 $\mu \mathrm{g})$, and Amoxicillin/Clavulanic acid $(20 / 10 \mu \mathrm{g})$. The three antibiotics were placed at distances of $30 \mathrm{~mm}$ (edge to edge) from the Amoxicillin/Clavulanic acid disc that was placed in the middle of the plate (Figure 4).

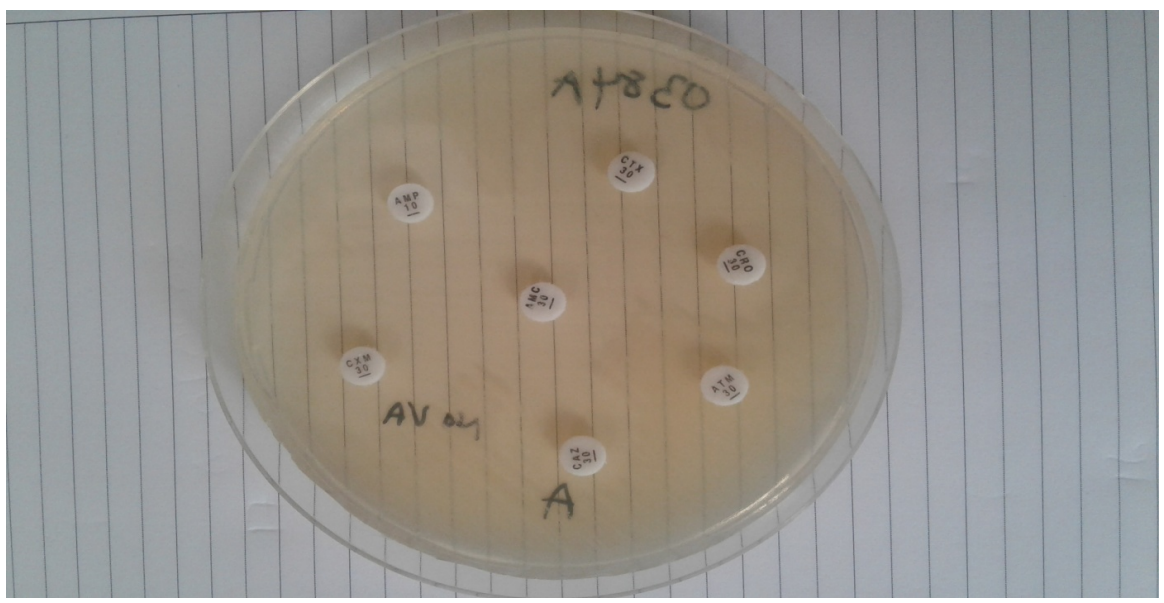

Figure 3. DST on MHA after inoculation with antibiotic disks and incubation for $24 \mathrm{hrs}$ at $37^{\circ} \mathrm{C}$.

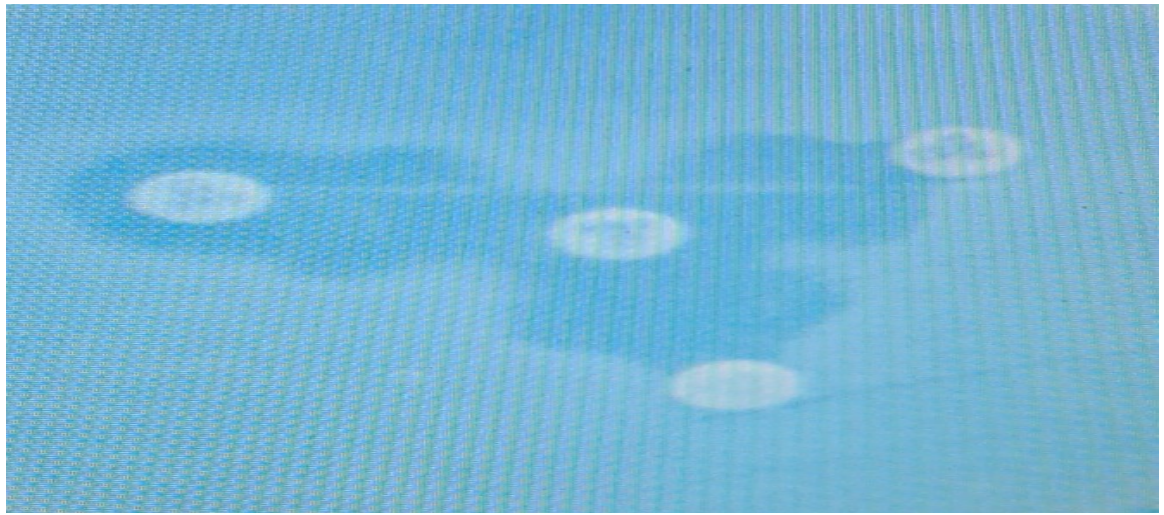

Figure 4. Double Disc Synergy (DDST). 
After 24-h incubation, if an enhanced zone of inhibition between either of the Cephalosporin antibiotics and the Amoxicillin/Clavulanic acid disc occurred, the test was considered positive. This indicated synergistic activity with Clavulanic acid and the presence of an ESBL [27].

\subsubsection{Phenotypic Confirmatory Disc Diffusion Test (Combined Disc Method)}

A Ceftazidime $(30 \mu \mathrm{g})$ disc was used alone and in combination with Clavulanic acid $(30 \mu \mathrm{g} / 10 \mu \mathrm{g})$ for phenotypic confirmation of the presence of ESBLs. A $\geq 5$ $\mathrm{mm}$ increase in zone diameter for either of the Cephalosporin discs and their respective Cephalosporin/Clavulanate disc was interpreted as ESBL producer (The antibiotics used were; ceftazidime $(30 \mu \mathrm{g})$ and ceftazidime-clavulanic acid $(20+10 \mu \mathrm{g})$, cefotaxime $(30 \mu \mathrm{g})$ and cefotaxime-clavulanic acid $(20+10 \mu \mathrm{g}))$ (Figure 5).

\subsubsection{Detection of ESBLs Encoding Genes}

Polymerase chain reaction (PCR) was carried out at Inqaba Biotechnical Industries (Pty) Ltd, Pretoria 0002, South Africa. The genes TEM, SHV and CTX-M, were amplified using primers (Table 2) [obtained from Inqaba Biotech 525 Justice Mahomed St, Muckleneuk, Pretoria, 0002, South Africa] and conditions as described in the Southwestern Uganda study [26]. Where archived isolates were thawed and subcultured, then incubated at $37^{\circ} \mathrm{C}$ for overnight.

\section{DNA Extraction}

For PCR, bacterial genomic DNA was extracted directly from colonies on subcultures grown on Trypticase soy agar with $5 \%$ sheep blood by boiling a dense suspension of an approximate $0.1 \mathrm{McFarland}$ standard in sterile distilled water. As the DNA template in the PCR assays, $2-3 \mu \mathrm{L}$ of the boiled cell suspension was used. PCR amplification of $b l a_{\mathrm{CTX}-\mathrm{M}}, b l a_{\mathrm{SHV}}$, and $b l a_{\mathrm{TEM}}$ genes in $K$. pneumoniae clinical isolates was performed by using a consensus primer pair specific to each type of $\beta$-lactamase as described [26]. A multiplex PCR was developed and used for simultaneous detection of bla $a_{\mathrm{CTX}-\mathrm{M}}(551 \mathrm{bp})$ and $b l a_{\mathrm{TEM}}(972$ bp) genes, other PCRs were performed for bla ${ }_{\mathrm{SHV}}(560)$. PCRs were carried out by

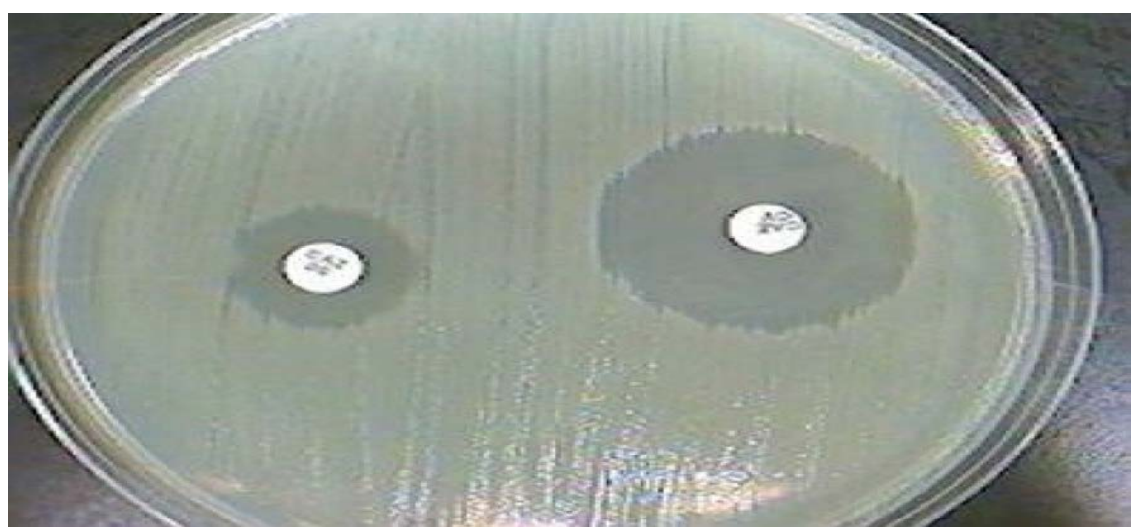

Figure 5. Combined disc test for ESBLs using ceftazidime $(30 \mu \mathrm{g})$ and ceftazidime-clavulanic acid $(20+10 \mu \mathrm{g})$. 
using the Hot Start DNA polymerase master mix (QIAGEN, Germantown, MD, USA) with 30 - 35 cycles at an annealing temperature of $52^{\circ} \mathrm{C}$ for bla $_{\text {СTX-M }}$ and $b a_{\mathrm{TEM}}$, and $50^{\circ} \mathrm{C}$ for $b a_{\mathrm{SHV}}$. PCR products were analyzed by using the agarose gel electrophoresis. The specificity of PCR amplicons on representative isolates was confirmed by DNA sequencing.

\section{DNA Sequencing}

For DNA sequencing, PCR products were purified by using the PCR Purification kit (QIAGEN) according to the manufacturer's instructions. The purified DNA amplicons were sequenced by using an ABI Prism BigDye Terminator (version 1.1) cycle sequencing ready reaction kit on the ABI 3500×1 DNA Analyzers, POP7 ${ }^{\mathrm{TM}}$ (ThermoScientific) at Inqaba Biotechnical Industries (Pty) Ltd. The CTX-M, TEM, and SHV gene sequences were compared with sequences in GenBank by using the NCBI basic local alignment search tool (https://blast.ncbi.nlm.nih.gov/Blast.cgi).

\subsection{Detection of Carbapenemase Production}

The Modified Hodge test (MHT), Boronic acid synergy test and the EDTA for the detection of carbapenemase production were performed as described [27].

\subsubsection{Modified Hodge Test (MHT)}

A Preparation of a $0.5 \mathrm{McF}$ arland standard suspension (using direct colony suspension) of $E$. coli $\mathrm{ATCC}^{\circledR}$ a25922 (the indicator organism) in saline, and was diluted to a ration 1:10 in saline, inoculated an MHA plate and a meropenem (10 $\mu \mathrm{l})$ disk on the plate, picked fresh test colonies, inoculated in a straight line out from the edge of the disk to the plate rim. Interpretation of both negative and positive tests was done according to CLSI 2017. [K. pneumoniae ATCC $^{\circledR}$ BAA- $1705^{\text {tw }}$ used] suggestive of KPC or OXA- 48 .

\subsubsection{The Boronic Acid Synergy Test}

Was done by adjusting the inoculum to a $0.5 \mathrm{McF}$ arland turbidity standard and then streaked on a plate by swabbing. The disks of $10 \mu \mathrm{g}$ meropenem and $400 \mu \mathrm{g}$ of phenyl Boronic Acid (PBA) (Carramore international limited, Oxoid Ltd, Wade Road, Basingstoke, and Hants, RG24 8PW, UK) were then placed on the inoculated plate $15 \mathrm{~mm}$ apart center to center, and incubated for 24 hours. The plate was then examined for the presence of an enhanced growth inhibition zone between the carbapenem disk and Boronic acid disk. The test with an enhanced growth inhibition zone was considered positive for the Carbapenem-Resistant Enterobacteriaceae, detection of KPC enzyme production, as described elsewhere [28].

\subsubsection{The Ethylenediammine Tetra Acetic Acid (EDTA) Test}

The Ethylenediammine tetra acetic acid (EDTA) test was used as performed earlier [29]; an overnight liquid culture of the test isolate was adjusted to a turbidity of 0.5 McFarland standard and spread on the surface of a Mueller Hinton Agar plate. Two $10 \mu \mathrm{g}$ imipenem discs were placed on the agar $15 \mathrm{~mm}$ apart (center to 
center). $10 \mu \mathrm{l}$ of 0.5 MEDTA was added to one of the imipenem disc to get the desired concentration of $750 \mu \mathrm{g}$. After incubation at $37^{\circ} \mathrm{C}$ overnight, increase of inhibition zone diameter of more $\geq 5 \mathrm{~mm}$ in the disc potentiated with the EDTA was interpreted as positive for metallo- $\beta$-lactamase production as described elsewhere (Figure 6) [30].

\subsubsection{Detection of Carbapenemase Encoding Genes}

Polymerase chain reaction (PCR) was carried out at Inqaba Biotechnical Industries (Pty) Ltd, Pretoria 0002, South Africa. The genes blaKPC, blaOXA-48 and blaVIM were amplified using primers (Table 5) [obtained from Inqaba Biotech 525 Justice Mahomed St, Muckleneuk, Pretoria, 0002, South Africa] and conditions as described in the [31]; where the presence of carbapenemase encoding genes was determined using primers targetingbla KPC, blaOXA-48 and blaVIM.

\section{DNA Extraction}

For PCR, bacterial genomic DNA was extracted directly from colonies on from fresh subcultures grown on Trypticase soy agar with 5\% sheep blood (SIGMA-ALDRICH, Co., 3050 Spruce Street, St. Louis, MO 63103 USA 314-771-5765) by boiling a dense suspension of an approximate of 0.1 McFarland standard in sterile distilled water. As the DNA template in the PCR assays, $2-3 \mu \mathrm{L}$ of the boiled cell suspension was used. PCR amplification of $b^{1} a_{0 \mathrm{XA}-48}$, bla${ }_{\mathrm{VIM}}$, and $b a_{\mathrm{KPC}}$ genes in $K$. pneumoniae clinical isolates was performed by using a consensus primer pair specific to each type of Carbapenemase as described [31]. A multiplex PCR was developed and used for simultaneous detection of $b l a_{\text {OXA-48 }}$ and $b a_{K P C}$ genes, other PCRs were performed for $b l_{\mathrm{VIM}}$. PCRs were carried out by using the HotStart DNA polymerase master mix (QIAGEN) with 30-35 cycles at an annealing temperature of $52^{\circ} \mathrm{C}$ for $b l a_{O X A-48}$ and $b l a_{\mathrm{kpc}}$, and $50^{\circ} \mathrm{C}$ for bla $a_{\mathrm{VIM}}$. PCR products were analyzed by agarose gel electrophoresis. The specificity of PCR amplicons on representative isolates was confirmed by DNA sequencing.

\section{DNA Sequencing}

For DNA sequencing, PCR products were purified by using the PCR Purification kit (QIAGEN) according to the manufacturer's instructions. The purified DNA amplicons were sequenced by using an ABI Prism BigDye Terminator (version 1.1) cycle sequencing ready reaction kit on the ABI 3500×l DNA Analyzers $\mathrm{POP7}^{\mathrm{TM}}$ (ThermoScientific) at Inqaba Biotechnical Industries (Pty) Ltd. The CTX-M,

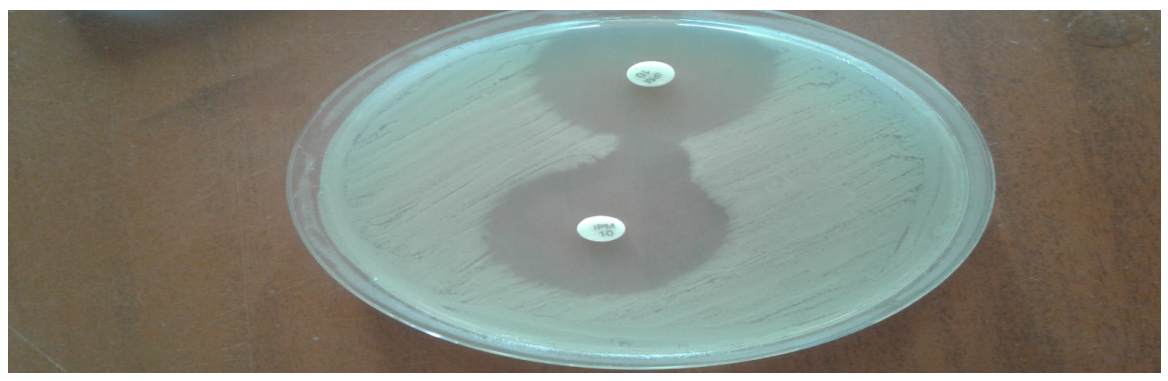

Figure 6. EDTA for metallo- $\beta$-lactamase testing. 
TEM, and SHV gene sequences were compared with sequences in GenBank by using the NCBI basic local alignment search tool (https://blast.ncbi.nlm.nih.gov/Blast.cgi).

\subsection{Phenotypic Screening for Hypervirulence (HV)}

For HV-phenotype determination, a standard bacteriologic loop (Greiner Bio-One Hungary $\mathrm{Kft}$ ) was used to stretch a mucoviscous string vertically from a colony. The formation of a viscous string of $>5 \mathrm{~mm}$ was confirmatory for the HV-positive phenotype (Figure 7) [1].

\section{Detection of Hypervirulence Encoding Genes}

No isolate passed string test thus no need to subject to conventional PCR for $\operatorname{rmp} A, \operatorname{rmp} A 2, \operatorname{mag} A$ and $K 2$ genes as described in previous studies [32].

\subsection{Data Analysis}

Data was coded and entered into the Microsoft Excel. Then, data was exported to STATA (version 12) for analysis. Descriptive statistics were done and results were presented in tables. A test of association was done using binary logistic regression. All the statistical tests were set for significance at $P$ value 0.05 . Odds ratios (OR) will be determined between wards and clinics with the following outcomes; 1) resistance to one antibiotic, 2) resistance to three different classes of antimicrobial agents: multi-drug resistance (MDR), phenotypic characteristics ESBLs, Carbapenem resistance and Hypervirulence.

\subsection{Ethical Consideration}

Ethical clearance was obtained from the Department of Microbiology, Mbarara University of Science and Technology (MUST), Faculty of Medicine Review Committee (FRC), Institutional Ethical Review Committee (IERC) of MUST.

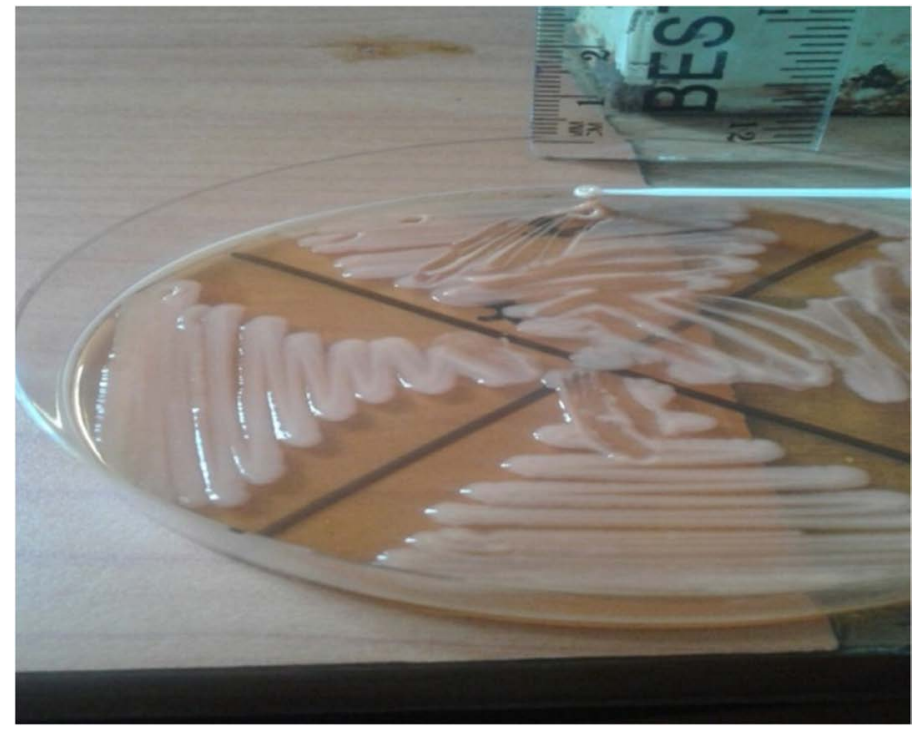

Figure 7. String test for the phenotypic testing of hypervirulence. 


\section{Results}

\subsection{Study Flow (Figure 8)}

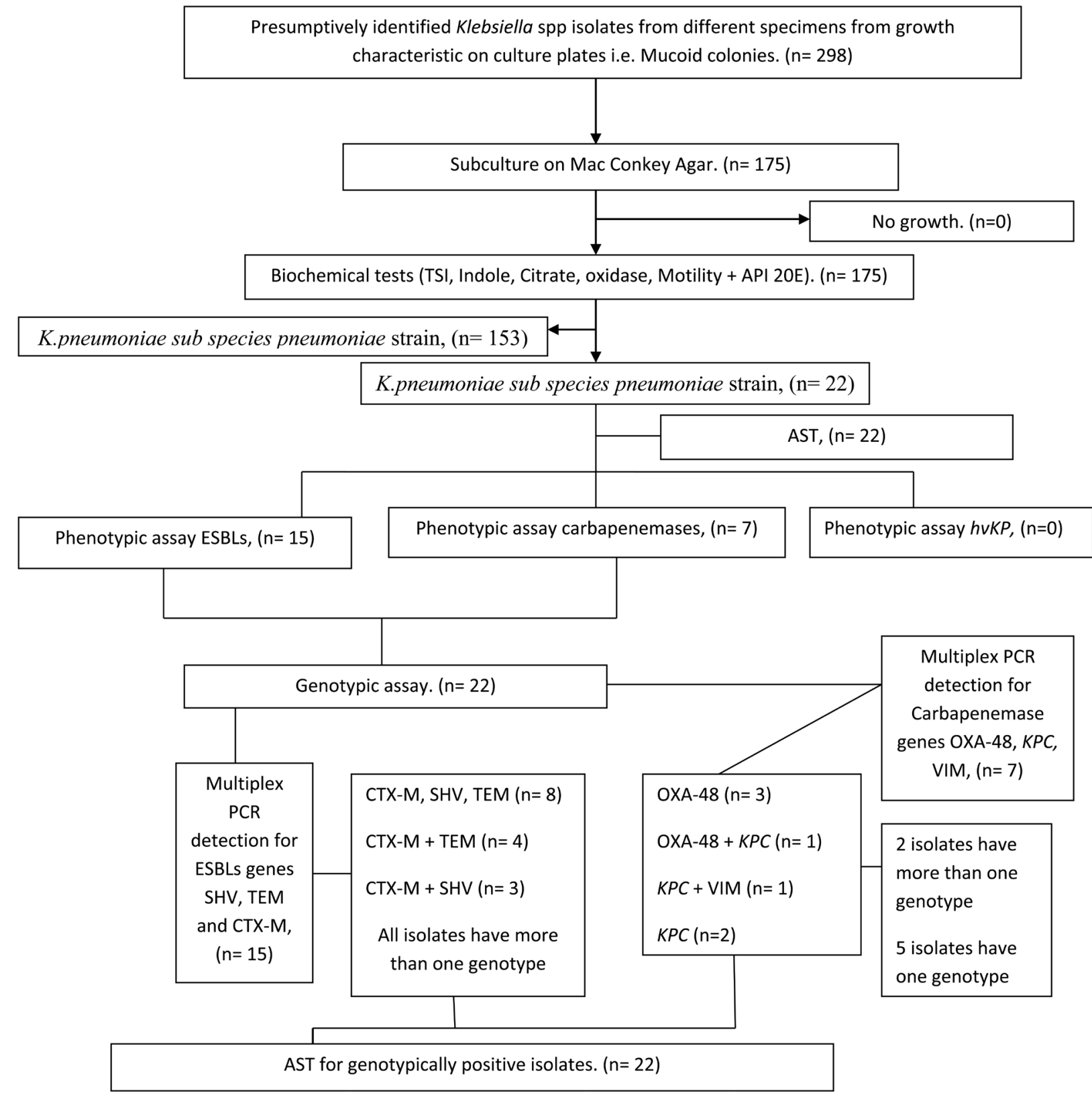

Figure 8. Study flow.

\subsection{Prevalence of Klebsiella spp.}

Out of 1055 samples from clinical patients between September 2018 and April 2019, Klebsiella spp. was reported in 298 cases through standard cultural and biochemical tests which later were archived at $-20^{\circ} \mathrm{C}$. The prevalence rate of Klebsiella spp was about $28 \%$ and non Klebsiella spp was $72 \%$ (Figure 9).

Highest prevalence was observed in urine sample at $36.56 \%$ followed by sputum $18.29 \%$, pus swabs $14.28 \%$, HVS $13.14 \%$, blood $8.56 \%$, ear swabs $3.43 \%$, pus 
aspirate, pleural fluid $1.71 \%$, aspirate, CSF, pus, tracheal aspirate, tracheal swabs $1.14 \%$, and ascetic fluid, chest pus, peritoneal fluid, posto auricle abscess, stool, throat swab, tracheal tube $0.57 \%$ (Figure 10). Females were more affected (63.43\%) with Klebsiella spp. than Males (36.57\%). Persons younger than 50 years irrespective of gender were more affected with Klebsiella spp., 70.86\%, and $29.14 \%$ greater or equal to 50years. High number of specimen came from OPD $50.85 \%$ followed by Medical ward 10.29\%, pathology 6.29\%, post natal 5.51\%, TOTO 4.00\%, MMIC 3.43\%, Ear, Nose, Throat(ENT) $2.86 \%$, ICU 1.71\%, gyn, nl, pead, private, emergency $1.14 \%$, chest clinic, female ward, ISS, must, oncology, pnw, post OPD, prison and TB ward 0.57\% (Figure 11).

\subsection{Subculturing and Biochemical Testing}

On subculturing, out of 175 isolates picked from archived samples gave out growth exhibiting colonies similar to Klebsiella species and were tested biochemically. Both the standard (Klebsiella pneumoniae ATCC 700603) and clinical isolates of Klebsiella ssp (175) were subjected to biochemical tests. Standard $K$. pneumoniae cultures showed positive reactions for urease production, citrate utilization, catalase reaction and fermentation of sugars like glucose, lactose, sucrose, and mannitol, Adonitol, Melibiose and Esculin. Organisms showed negative

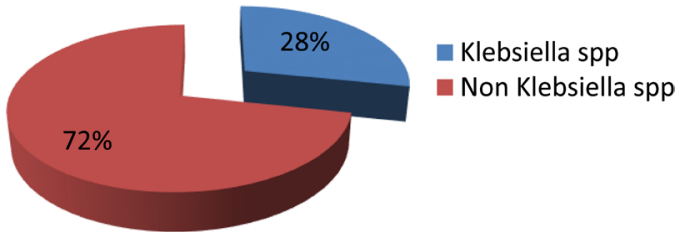

Figure 9. Prevalence rate of Klebsiella spp isolates among clinical specimens collected from September 2018 to April 2019.

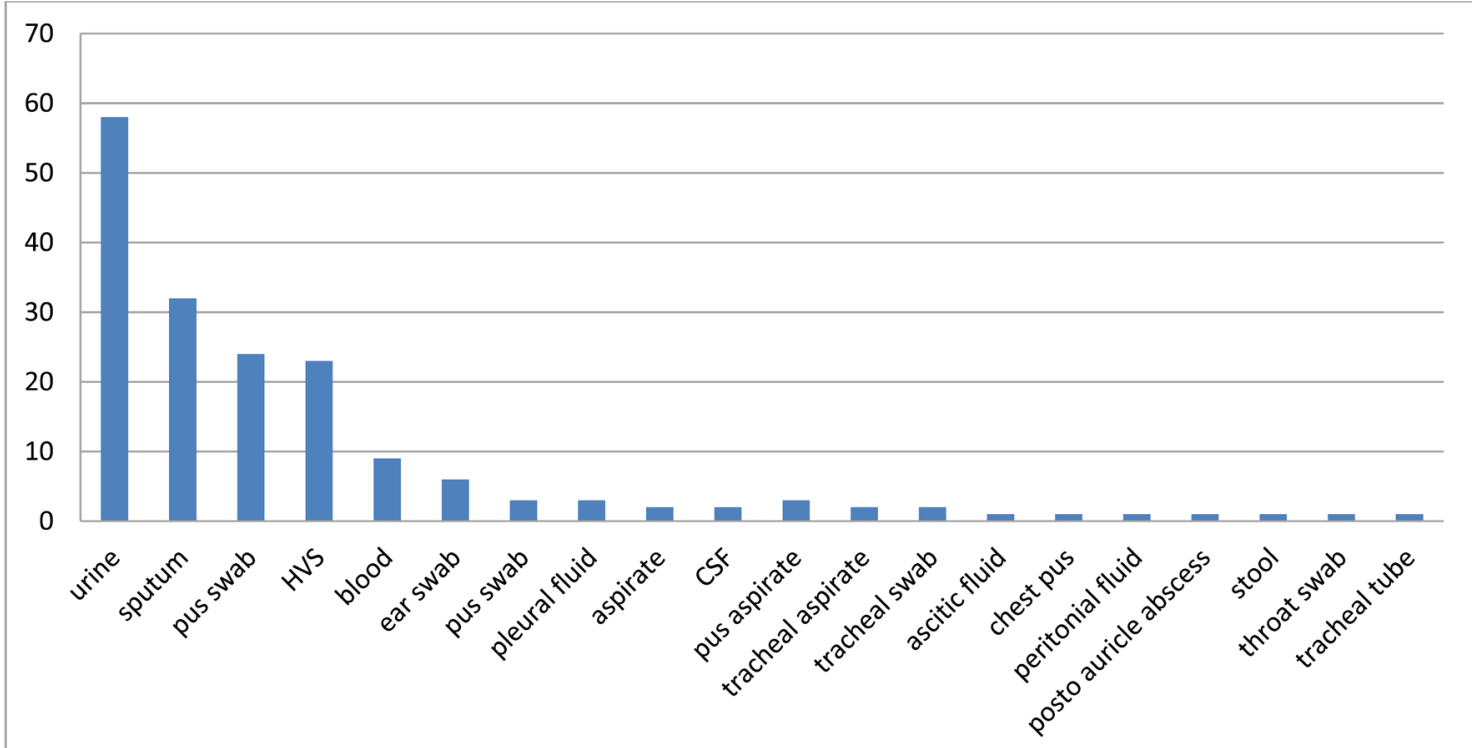

Figure 10. Prevalence of Specimens received at Microbiology Laboratory, Department of Microbiology, MUST received between September 2018 and April 2019 end. 
test for indole production, motility, and oxidase. There was no $\mathrm{H}_{2} \mathrm{~S}$ production on Triple Sugar Iron agar (TSI) giving A/A for both slope and butt. Fifty eight (58) clinical isolates showed common biochemical reaction pattern for Klebsiella pneumoniae being positive to glucose, lactose, sucrose, and mannitol and negative to oxidase and indole. On subjection onto some rare sugars (Adonitol, Melibiose, Esculin and dulcitol) on API 20E, twenty two (22) of them exhibited reactions attributable to majority of $K$. pneumoniae sub species pneumoniae strain (Figure 12), being positive to Adonitol, Melibiose, Esculin, urease and citrate. The rest of the isolates showed a variation in reaction to the used biochemical tests.

\subsection{Antibiotic Sensitivity Patterns of Klebsiella pneumoniae}

Antibiotic sensitivity testing of twenty two (22) confirmed $K$. pneumoniae clinical isolates was done on Muller-Hinton agar plates. On the basis of resistance to antibiotic, strains were categorized into three groups i.e. susceptible(S), resistant (R) and intermediate (I) as shown in Table 1. Twelve antibiotics which included

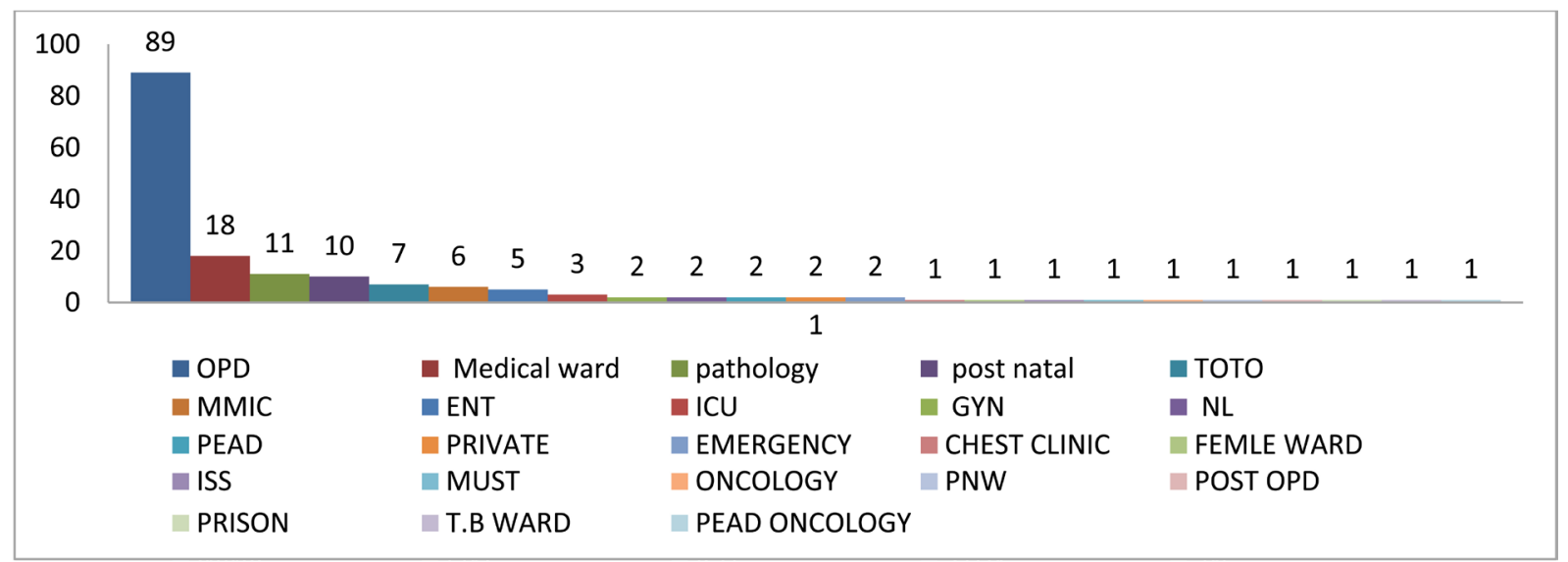

Figure 11. Occurrence of Specimens by ward received at Microbiology Laboratory, Department of Microbiology, MUST received between September 2018 and April 2019 end.

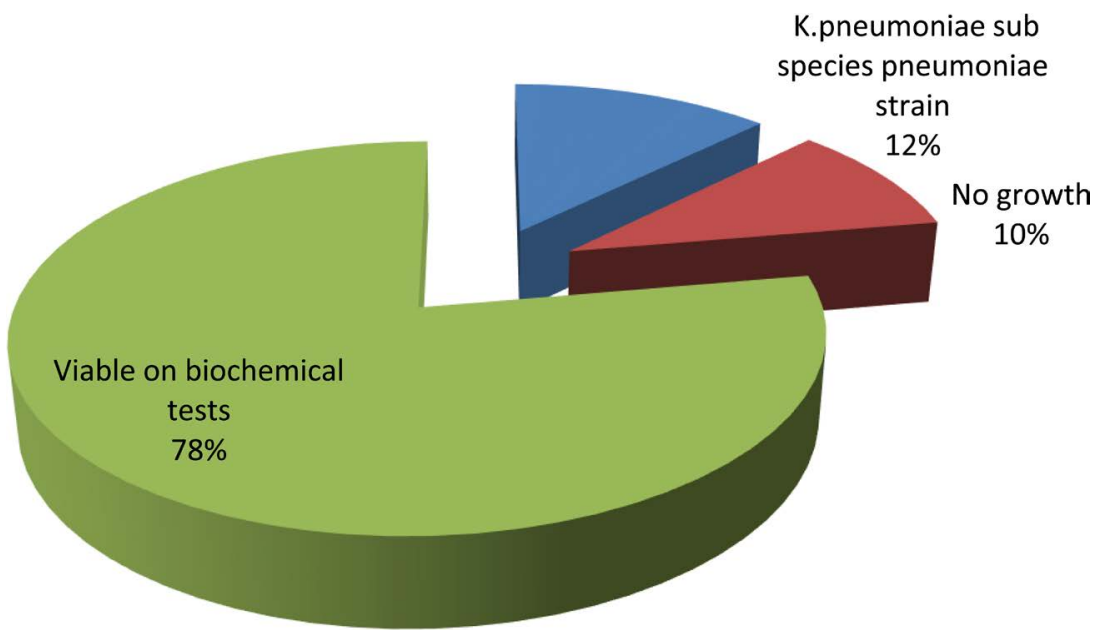

Figure 12. Prevalence of K. pneumoniae sub species pneumoniae strain from clinical isolates. 
amoxicillin/clavulanate $(20 / 10 \mu \mathrm{g})$, cefuroxime $(30 \mu \mathrm{g})$, ceftriaxone $(30 \mu \mathrm{g})$, cefotaxime $(30 \mu \mathrm{g})$, ceftazidime $(30 \mu \mathrm{g})$, meropenem $(30 \mu \mathrm{g})$, gentamicin $(10 \mu \mathrm{g})$, ciprofloxacin $(5 \mu \mathrm{g})$, nitrofurantoin $(300 \mu \mathrm{g})$, cefepime $(30 \mu \mathrm{g})$, piperacillin/tazobactam $(100 / 10 \mu \mathrm{g})$ and cefoxitin $(30 \mu \mathrm{g})$ were used.

The pattern of antimicrobial susceptibility among the $22 \mathrm{~K}$. pneumoniae isolates showed that $72.7 \%$ was resistant to Ceftriaxone, $63.7 \%$ was resistant to (Amoxicillin/Clavulanate), 54.5\% was resistant to Gentamicin, $45.5 \%$ was resistant to Cefepime, $31.8 \%$ was resistant to Ciprofloxacin and Cefoxitin, $27.3 \%$ was resistant to Nitrofurantoin and Cefuroxime, $22.7 \%$ was resistant to piperacillin/tazobactam, $18.2 \%$ was resistant to Meropenem, Ceftazidime and cefotaxime was resistant to $9.1 \%$ (Table 1, Figure 13).

MDR was observed at $72.7 \%$ but unique isolate that kept appearing in the zones of clearance which at first was thought to be a contaminant was subcultured and

Table 1 . Susceptibility patterns of confirmed $K$. pneumoniae isolates $(N=22)$.

\begin{tabular}{cccc}
\hline Antibiotics & Sensitive & Intermediate & Resistant \\
\hline Amoxicillin/Clavulanate $(20 / 10 \mu \mathrm{g})$ & $3(13.64 \%)$ & $5(22.73 \%)$ & $14(63.65 \%)$ \\
Cefuroxime $(30 \mu \mathrm{g})$ & $11(50.00 \%)$ & $5(22.73 \%)$ & $6(27.27 \%)$ \\
Ceftriaxone $(30 \mu \mathrm{g})$ & $1(4.45 \%)$ & $5(22.82 \%)$ & $16(72.73 \%)$ \\
Ceftazidime $(30 \mu \mathrm{g})$ & $14(63.36 \%)$ & $6(27.27 \%)$ & $2(9.09 \%)$ \\
Meropenem $(30 \mu \mathrm{g})$ & $17(77.28 \%)$ & $1(4.54 \%)$ & $4(18.18 \%)$ \\
Gentamicin $(10 \mu \mathrm{g})$ & $5(22.73 \%)$ & $5(22.73 \%)$ & $12(54.54 \%)$ \\
Ciprofloxacin $(5 \mu \mathrm{g})$ & $13(59.09 \%)$ & $2(9.09 \%)$ & $7(31.82 \%)$ \\
Nitrofurantoin $(300 \mu \mathrm{g})$ & $8(36.36 \%)$ & $8(36.36 \%)$ & $6(27.28 \%)$ \\
Cefepime $(30 \mu \mathrm{g})$ & $9(40.90 \%)$ & $3(13.63 \%)$ & $10(45.47 \%)$ \\
Cefoxitin $(30 \mu \mathrm{g})$ & $15(68.18)$ & $2(9.09 \%)$ & $5(22.73 \%)$ \\
Cefotaxime $(30 \mu \mathrm{g})$ & $10(45.47 \%)$ & $5(22.73 \%)$ & $7(31.82 \%)$ \\
\hline Piperacillin $/$ tazobactam $(100 / 10 \mu \mathrm{g})$ & $14(63.36 \%)$ & $6(27.27 \%)$ & $2(9.09 \%)$ \\
\hline
\end{tabular}

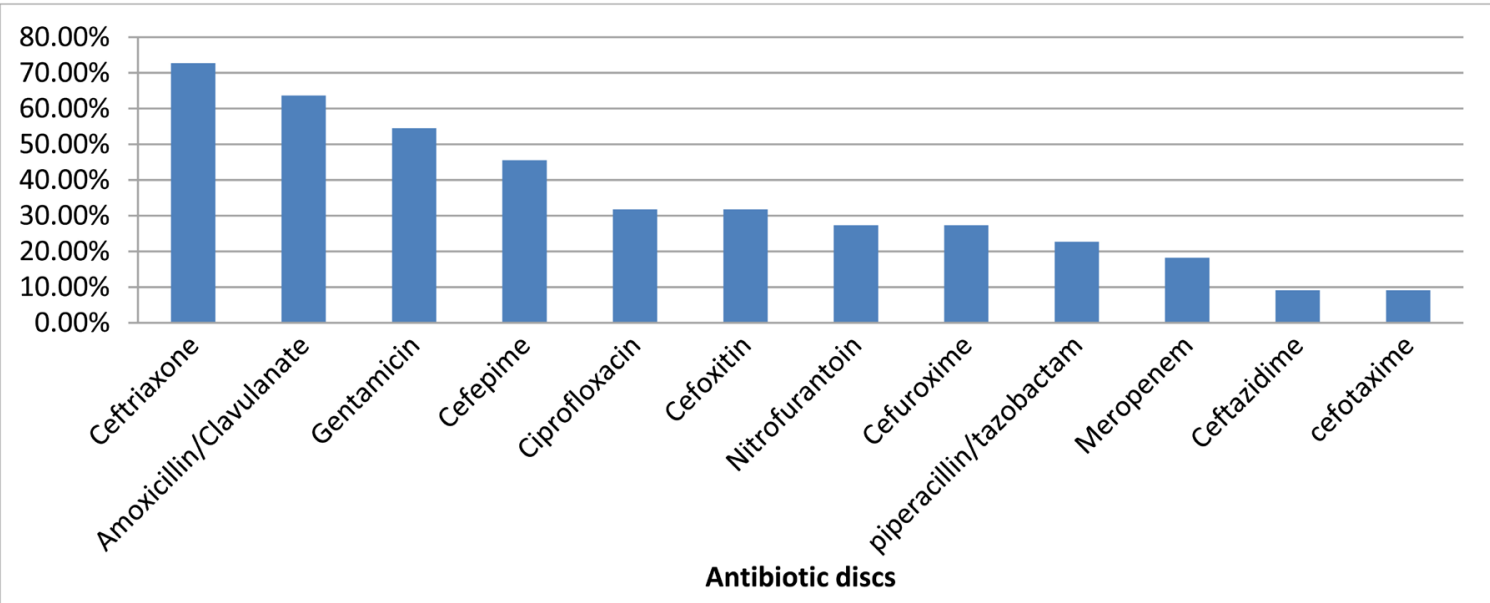

Figure 13. Percentage Resistance of confirmed $K$. pneumoniae isolates to different used antibiotics. 
later revealed to be a Klebsiella spp on biochemical test basis was found out to be resistant to all tested 12 antibiotics.

\subsection{Potential ESBL among Biochemically Positive Klebsiella pneumoniae Isolates}

All the confirmed 22 bacterial pathogens were tested. In order to improve the sensitivity, we used ceftazidime, cefotaxime, and ceftriaxone antibiotics to screen for ESBL activity. The combined disk test indicated that 15 (68.18\%) isolates presented inhibition of clavulanic acid.

E. coli (ATCC 25922) negative ESBLs and $K$. pneumoniae (ATCC 700603) positive ESBLs were used as controls.

\subsubsection{PCR Amplification for ESBLs Genes}

Table 2. Primer sets for amplification of ESBLs resistance genes.

\begin{tabular}{clcc}
\hline Gene & \multicolumn{1}{c}{ Primer sequence $\left(5^{\prime} \rightarrow 3^{\prime}\right)$} & TM $\left({ }^{\circ} \mathrm{C}\right)$ & Amplicons size (bp) \\
\hline \multirow{2}{*}{ CTX-M } & $\begin{array}{l}\text { Forward: CGCTTTGCGATGTGCAG } \\
\text { Reverse: ACCGCGATATCGTTGGT }\end{array}$ & 52 & 551 \\
& $\begin{array}{l}\text { Forward: ATGCGTTATATTCGCCTGTG } \\
\text { SHV }\end{array}$ & 52 & 972 \\
Reverse: TGCTTTGTTATTCGGGCCAA & $\begin{array}{l}\text { Forward: AAACGCTGGTGAAAGTA } \\
\text { Reverse: AGCGATCTGTCTAT }\end{array}$ & 45 & 560 \\
\hline
\end{tabular}

\subsubsection{Prevalence of ESBLs Genes}

All ESBL $K$. pneumoniae tested on PCR assay had at least two ESBL genes showing that $8 / 15$ (53.33\%) possessed all the genes (i.e. CTX-M, SHV, TEM), 4/15 (26.67\%) had both CTX-M and TEM while 3/15 (20.00\%) had CTX-M and SHV. CTX-M (100\%) i.e. in all isolates, TEM (80\%) and SHV (73.3\%) (Table 3).

\subsection{Prevalence of Carbapenemase Active Isolates Based on Phenotypic Tests}

Regardless of their ESBL result, all the 22 isolates were tested for carbapenemase production. Among the $22 \mathrm{~K}$. pneumoniae isolates, 7 (31.82\%) were positive for the production of carbapenemases which of these, 1/7 (14.28\%) was detected by MHT method, 4/7 (57.14\%) by Boronic acid test and 2/7 (28.58\%) by the EDTA test (Table 4).

Prevalence of Carbapenemase Genes

Based on the PCR assay, 3/4 [(75\%) 42.86\%] detected carbapenemases by Boronic

Table 3. Prevalence of ESBLs Genes $(N=15)$.

\begin{tabular}{ccc}
\hline Genes & Isolates & \% age \\
\hline CTX-M, SHV, TEM & 8 & 53.33 \\
CTX-M, TEM & 4 & 26.67 \\
CTX-M, SHV & 3 & 20.00 \\
\hline
\end{tabular}


Acid test all showed to be positive for OXA-48 gene for which $1 / 4$ [(25\%) $14.28 \%]$ of them had both OXA-48 and KPC gene, 1/2 [(50\%) 14.28\%] isolates detected by EDTA test was positive for both KPC and VIM the other 1/2 [(50\%) $14.28 \%]$ had KPC and that detected by MHT method showed KPC gene [(100\%) 14.28\%]. The Boronic Acid test showed a strong association with detection of OXA-48 gene type $(\mathrm{P}=0.000)$ and KPC $(\mathrm{P}=0.045)$ carbapenemases compared to VIM type metallo- $\beta$-lactamases $(\mathrm{P}>0.05$ ) (Table 6$)$.

\subsection{Prevalence of the Hypervirulent $K$ pneumoniae}

No isolate exceeded a $3 \mathrm{~mm}$ stretch with a biological loop.

\subsection{Antibiogram for the Genotypically Confirmed $K$. pneumoniae for ESBLs and Carbapenemases Isolates}

Seven antibiotics which included Cefoperazone/Sulbactam, Ciprofloxacin, Ertapenem, Imipenem, Levofloxacin, Meropenem and Colistin were used.

The pattern of antimicrobial susceptibility among the $22 \mathrm{~K}$. pneumoniae isolates irrespective of the confirmed resistance showed that $31.8 \%$ was resistant to Ciprofloxacin, $18.2 \%$ was resistant to Meropenem, $13.63 \%$ was resistant to Colistin, 9.09\% was resistant to Ceftazidime/avibactam and Levofloxacin, $4.54 \%$

Table 4. Phenotypic tests.

\begin{tabular}{ccc}
\hline Test & Isolates & \%age \\
\hline MHT & 1 & 14.28 \\
Boronic Acid & 4 & 57.14 \\
EDTA & 2 & 28.58 \\
\hline
\end{tabular}

Table 5. Primer sets for amplification of carbapenemase resistance genes.

\begin{tabular}{clcc}
\hline Gene & \multicolumn{1}{c}{ Primer sequence $\left(5^{\prime} \rightarrow \mathbf{3}^{\prime}\right)$} & TM $\left({ }^{\circ} \mathrm{C}\right)$ & Amplicons size $(\mathbf{b p})$ \\
\hline \multirow{2}{*}{ bla-VIM } & $\begin{array}{l}\text { Forward: GATGGTGTTTGGTCGCATA } \\
\text { Reverse: CGAATGCGCAGCACCAG }\end{array}$ & 52 & 390 \\
\multirow{2}{*}{ bla-KPC } & $\begin{array}{l}\text { Forward: CATTCAAGGGCTTTCTTGCTGC } \\
\text { Reverse: ACGACGGCATAGTCATTTGC }\end{array}$ & 52 & 498 \\
\multirow{2}{*}{ ba-OXA-48 } & $\begin{array}{l}\text { Forward: GCTTGATCGCCCTCGATT } \\
\text { Reverse: GATTTGCTCCGTGGCCGAAA }\end{array}$ & 50 & 238
\end{tabular}

Table 6. Prevalence of carbapenemase genes.

\begin{tabular}{cccc}
\hline Genes & Isolates & \% per Isolate & \% per Resistance \\
\hline OXA-48 (Boronic Acid) & 3 & 75 & 42.86 \\
OXA-48 and KPC (Boronic Acid) & 1 & 25 & 14.28 \\
KPC and VIM (EDTA) & 1 & 50 & 14.28 \\
KPC (EDTA) & 1 & 50 & 14.28 \\
$K P C(\mathrm{MHT})$ & 1 & 100 & 14.28 \\
\hline
\end{tabular}


was resistant to Ertapenem and there was no resistance for Imipenem (Table 7, Figure 14).

\section{Discussion}

\subsection{Prevalence of Klebsiella spp.}

The increased prevalence of Klebsiella spp among clinical isolates has been of a greater concern worldwide as it has been one the organism showing a higher resistance to available antibiotics. In the present study, a $28 \%$ prevalence rate of Klebsiella was observed among clinical isolates at MRRH arriving at MUST Microbiology Laboratory which is an increased prevalence rate compared to the past studies done at the same institution with a rate of $20.26 \%, 12.7 \%$ [26] [33] respectively but lower in a study done by Mutiibwa and Tumusiime at $37.9 \%$ [34] at the same institution. Different rates were seen at different institution but same regions like $52 \%$ at Kabale, $22.4 \%$ at Mulago, $14.4 \%$ at Mbale and $10.2 \%$ in Tanzania [35] [36] [37] [38] may be acceptable because the prevalence of Klebsiella infections varies in different geographical locations [39].

\subsection{Prevalence of $K$ pneumoniae}

A number of studies have shown different prevalence of $K$. pneumoniae among

Table 7. Susceptibility patterns of genotypically confirmed $K$. pneumoniae isolates $(N=$ 22).

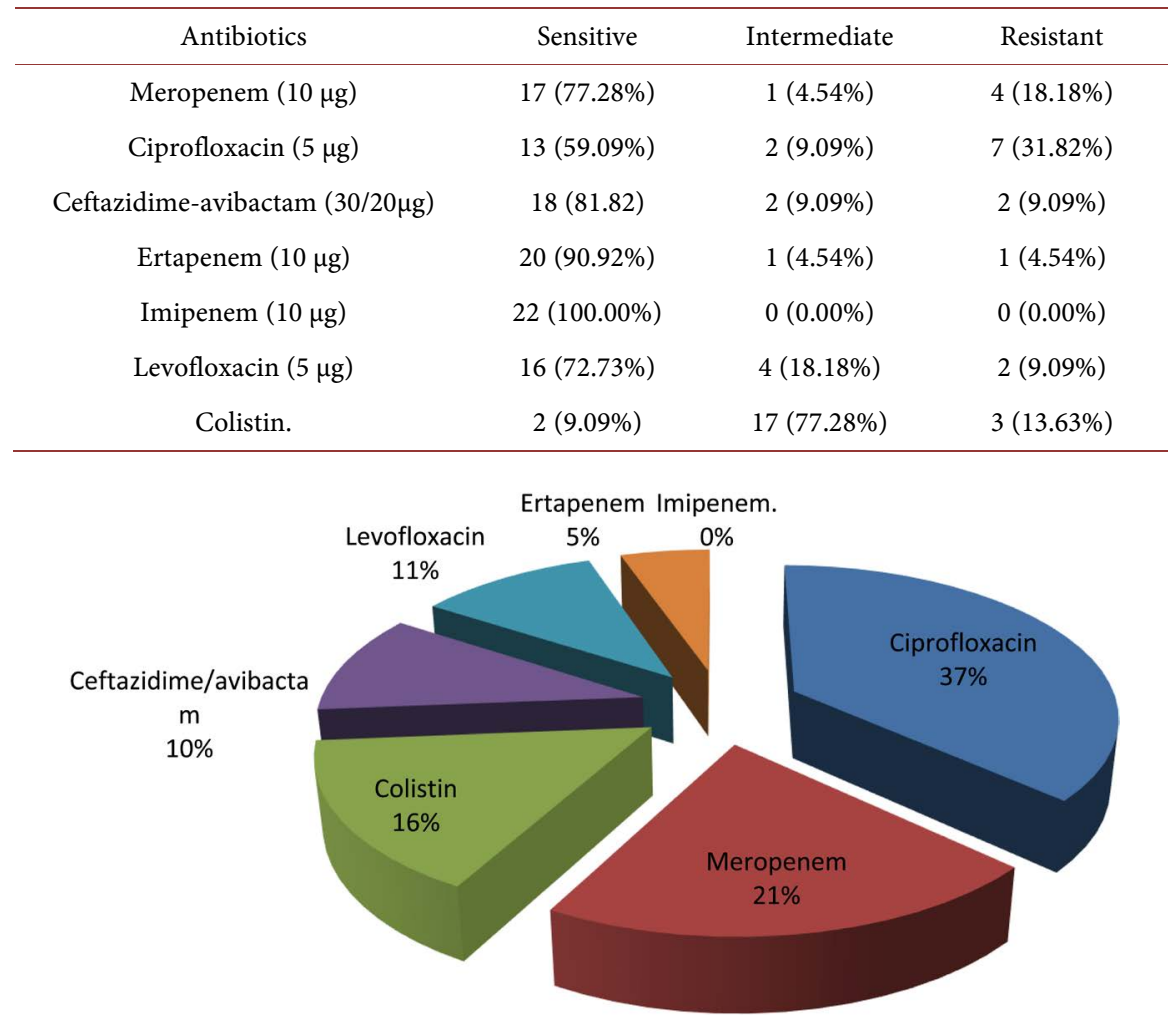

Figure 14. Number of Resistant Isolates against antibiotic discs. (Renamed from Figure 13 to Figure 14 and percentage calculated). 
isolates determined in different study places putting it at around 3\% to $12 \% ; 3 \%$ [40], 5\% [41]. The prevalence rate of Klebsiella pneumoniae was at $12.57 \%$ in this study which is in the agreement with the previous study done at MRRH, Bushenyi and central districts of Uganda [26] [40] [42] [43] but lower to the other study done at the same institution putting it at $18.6 \%$ [44], same region $20 \%$ at Mulago [45], 15\% [35] but the most alarming figures are seen in studies conducted at Mulago, MRRH at 52.2\%, 28.7\%, 50.0\% [29] [46] [47].

\subsection{Distribution of Klebsiella spp among Different Specimens, Age and Gender}

Prevalence was higher in Females (63.43\%) than in the Male (36.57\%) due to mechanical, hormonal and physiological changes at adolescence, during pregnancy and pre/post menopause. Females who were 50 years of age and above were found to be more infected with Klebsiella spp associated infection probably due to reduced immunity and pre/post menopause whereas Males between 18 and 50 years of age had the highest incidence of infection on age group greater than 50 years due to poor health living styles like increased sexual activities and living a dangerous life which is much supported by a number studies done around [40] [46].

High number of specimens came from OPD at $50.85 \%$ and most of the Klebsiella were recovered from urine samples irrespective of age and gender, followed by sputum and pus swab Kateregga et al., Ampaire et al., also reported that urine is the principal source of Klebsiella [44] [46] but not supported by a number of studies which have different specimen for isolation and different ward which could be due to a number of reasons like the aim of the study or even the months of collection since due to environmental pressure, during the warmest months may lead to an increase in Klebsiella infection which could be due to characteristics of Klebsiella which might have some role on such seasonal variation. Klebsiella is the most heat tolerant among all enteric pathogens [48] having maximal specific growth rate at $37^{\circ} \mathrm{C}$. In addition, they are believed to survive at higher humidity [49].

\subsection{Antibiotics Susceptibility Pattern for Confirmed K. pneumoniae Isolates}

All were highly resistant to ceftriaxone $72.73 \%$, 54.5\%Gentamicin, $45.5 \%$ Cefepime, 31.8\% Ciprofloxacin and Cefoxitin, 27.3\% Nitrofurantoin and Cefuroxime, $18.2 \%$ Ceftazidime and cefotaxime 9.1\%. Gentamicin like aminoglycosides has a good record against clinically important Gram-negative bacilli [50] as it is reflected in this study since resistance is moderate. Among the $\beta$-lactamase inhibitor combination agents, piperacillin-tazobactam was most active, inhibiting $68.18 \%$ of the strains; $13.64 \%$ were inhibited by Amoxicillin/Clavulanate which is supported elsewhere like studies done. The isolates showed a variation to a number of studies which could be due to the misuse or overuse of the antibiotics coupled with weak infection control measures and this alerts the health care sys- 
tem to work hard on the health facilities infection control.

\subsection{Multi-Drug Resistance}

The present study showed that the level of MDR in $K$. pneumoniae $(72.7 \%)$ which was comparable with studies conducted in Sierra Leone (73.3\%) [51]. However, lower than studies conducted in Brazil (84\%), Gondar, Ethiopia (95.6\%) and Equatorial Guinea (91.7\%) [52] [53] [54]. The difference in MDR level among $K$. pneumoniae in this study might be due to most $K$. pneumoniae being isolated from Urine specimens collected from hospital inpatients. Co-existence of genes in the same isolate with at least one or two other ESBLs or $\mathrm{CP}$ genes in these isolates among which it was detected, probably explain why these isolates were multidrug resistant.

\subsection{Prevalence of Phenotypic ESBL-Producing $K$. pneumoniae}

The occurrence of ESBL among clinical isolates greatly varies worldwide and geographically, and is rapidly changing over time [55]. In the present study, ESBL phenotypes were found to be positive in $15(68.18 \%)$ isolates demonstrating a high prevalence of ESBL production in $K$. pneumoniae isolates, at MRRH, south western Uganda.

Similar results were reported in studies done in Mulago (72.7\%), Bahir-Dar, Ethiopia (69.8\%) and Jimma, Ethiopia (70.4\%) [46] [56]. However, our result is higher compared to other reports from Kenya (31.4\%), Kasese (23\%) [42] [57]. But a number of studies around the region have reported high percentages of ESBL-producing isolates, 92.3\% in Uganda [58], 92\% at Kabale Regional Referral Hospital [35] 76\% K. pneumoniae [59], 84.2\% [60] in Ethiopia. The high prevalence of ESBL-producing isolates described in this study may be due to the selective pressure caused by the use of 3rd generation cephalosporins [61]. Lack of antibiotic surveillance, antibiotics misuse, and weak infection control measures may also contribute to the high magnitude of ESBL.

\subsection{Prevalence of Genotypic ESBL-Producing $K$. pneumoniae}

In the present study, genotypic survey on 15 confirmed ESBL phenotype strains by Multiplex PCR revealed that all isolates (100\%) were positive genotypically for at least two of the studied genes. The PCR results showed that among ESBL gene families, blaCTX-M (100\%)was the most prevalent in the isolates, followed by blaTEM ( $80 \%)$ and then blaSHV $(73.3 \%)$. These results are in agreement with other studies, such as that done at MRRH [26], which reported that, $70 \%$ of CTX-M was the highest followed by TEM (47\%) and SHV (34); the study in Kenya [62] showed that CTX-M gene was found in $88.5 \%$ followed by TEM (34.6\%) and in Sudan; showed that CTX-M gene was found in $86.4 \%$ of $K$. pneumonia [63]. Expression of more than one resistance gene; $b l a_{\mathrm{CTX}-\mathrm{M}} / b_{\mathrm{SHV}}$ $b l a_{\mathrm{CTX}-\mathrm{M}} /$ bla $_{\mathrm{TEM}}$, bla $a_{\mathrm{SHV}} /$ bla $_{\mathrm{TEM}}$ and $b l a_{\mathrm{CTX}-\mathrm{M}} /$ bla $_{\mathrm{SHV}} /$ bla $a_{\mathrm{TEM}}$ was observed in $15 / 15$ isolates which are supported by a number of studies like that done by Acaku et 
al., showing that one bacterial isolate can express more than one resistance gene [26].

\subsection{Prevalence of Phenotypic Carbapenem-Producing K. pneumoniae}

Carbapenem resistance has shown a varying prevalence rate all over the world has been reported in places worldwide, such as Argentina, Egypt, India, Nigeria, and the Netherlands [64]-[69] which are representative of each continent. In the present study, the prevalence of carbapenemase-producing $K$. pneumoniae was $31.82 \%$ which is supported by a number of studies done around like; $23.2 \%$ in Kenya [70], 22.4\% Uganda [29], 12.8\% [71], which is much lower than rates portrayed in others studies like; $10.3 \%$ [44] at MRRH, Ethiopia $12.1 \%$ [60], 1.87\% [59], but lower than prevalence rate in Tanzania 35\% [31] and 59.1\% [67]. The high prevalence in this study might be due to the fact that no restricted rules governing antibiotics in Uganda.

A great concern is occurrence of their resistance is worrying because these enzymes-encoding genes for this kind of resistance might be imported from abroad probably, or they emerge locally and spread by gene transfer [12].

The emergence of these carbapenemase-producing $K$. pneumoniae isolates in the hospital settings may be due to multiple factors including uncontrolled antibiotic usage, inappropriate dosing regimens, widespread counterfeit and substandard antibiotics, and local hospital practices concerning isolation of patients with multiresistant pathogens which is poorly managed but can also be community-acquired as they have also been isolated from the common water sources [67].

\subsection{Prevalence of Genotypic Carbapenem-Producing K. pneumoniae}

In the present study, the genes characterized included; bla OXA-48 and blaKPC at $57.14 \%$ and bla VIM at 14.28 appearing in $C P K P(31.82 \%)$ which is different from a study at Mulago; blaVIM (10.7\%), followed by blaOXA-48 (9.7\%), blaIMP (6.1\%), blaKPC (5.1\%) and blaNDM-1 (2.6\%) appearing in (52.2\%) Klebsiella pneumoniae [29], while at Mbarara hospital, VIM and OXA-48 CR determinants were registered appearing in $30.60 \%$ CPKP supporting our study [44], in Tanzania Molecular analysis of CRE at a tertiary hospital in Mwanza established by multiplex PCR revealed that the principal CR genes were IMP (21.6\%), followed by VIM (12.3\%), OXA-48 (4.9\%), then KPC (3.5\%), and NDM (3.1\%) appearing in $11 \%$ of $K$. pneumoniae [31]. In Kenya, CP $K$. pneumoniaeVIM-2 genes were isolated in Nairobi [72] were Seven carbapenem-resistant NDM-1-positive Klebsiella pneumoniae isolates were recovered from patients hospitalized between 2007 and 2009 and all isolates carried the $b l a_{\mathrm{NDM}-1}$ carbapenemase gene while Whole Genome sequencing (WGS) was employed to identify NDM-1 like CR genes in $K$. pneumoniae isolates at Kilifi County Hospital were no isolates were found to be resistant to carbapenems but a plasmid with the genetic architecture 
of a known New Delhi metallo- $\beta$-lactamase-1 (NDM)-carrying plasmid in 25 isolates [71].Variation of these genes in different studies maybe due to the fact that beta-lactamases by gram-negative organisms are usually secreted especially when antibiotics are present in the environment [73].

\section{Study Limitations}

The study was limited to MRRH, thus observation bias may have occurred during observational assessment

Samples were not collected from Health workers because it is a sensitive issue thus association was not done.

No history was taken about antibiotic intake, thus may not have given us the association to development of resistance among patients.

Limited funds have prevented us from using more advanced molecular typing technologies such as multi-locus sequence typing (MLST) in order to investigate the molecular epidemiology of ESBLS-KP and CRKP in this geographical region.

\section{Conclusions and Recommendations}

The high prevalence rate for both ESBL-producing (68.18\%) and Carbapenemaseproducing $(31.82 \%) K$. pneumoniae among clinical isolates is an important problem for both microbiologists and clinicians thus recommending as follows;

In resource-limited settings like at MRRH, double-disk synergy method can be implemented for screening and confirming ESBL production, MHT, Boronic Acid test and EDTA tests for all resistant isolates to Meropenem/or Imipenem can be implemented for screening and confirming Carbapenemase-production that might give valuable information for appropriate antibiotics selection and controlling the spread of these modes of resistance.

Routine infection preventions strategies such as compliance to hand hygiene principles, rational use of antimicrobial agents and surveillance of AMR are urgently needed to prevent and control the spread of antimicrobial-resistant pathogens in the healthcare facilities.

The increasing prevalence of CRE mainly due to carbapenemase production is alarming in clinical practice, specifically in areas where no carbapenems are sold. This study provides a clearer picture of the current CRE scenario in the hospital setup, and hence, identifying factors that induce carbapenemase production in the absence of carbapenems prescription is essential for control of CRE dissemination within the community.

Further studies are needed to identify the most common clones of both ESBLs-KP and CRKP genes at MRRH.

\section{Conflicts of Interest}

The authors declare no conflicts of interest regarding the publication of this paper. 


\section{Funding}

No funding was received for this work it was personally funded.

\section{References}

[1] Struve, C., et al. (2015) Mapping the Evolution of Hypervirulent Klebsiella pneumoniae. MBio, 6, e00630-15. https://doi.org/10.1128/mBio.00630-15

[2] Friedländer, C. (1882) Über die Schizomyceten bei der acuten fibrösen Pneumonie. Archiv für pathologische Anatomie und Physiologie und für klinische Medicin, 87, 319-324. https://doi.org/10.1007/BF01880516

[3] Stürchler, D. (2016) Klebsiella and Klebs the Person behind the Name. Travel Medicine and Infectious Disease, 14, 654. https://doi.org/10.1016/j.tmaid.2016.11.003

[4] Calfee, D.P. (2017) Recent Advances in the Understanding and Management of Klebsiella pneumoniae. F1000 Research, 6, 1760. https://doi.org/10.12688/f1000research.11532.1

[5] Tille, P. (2015) Bailey \& Scott's Diagnostic Microbiology E-Book. Elsevier Health Sciences.

[6] Pan, Y.-J., et al. (2015) Identification of Capsular Types in Carbapenem-Resistant Klebsiella pneumoniae Strains by wzc Sequencing and Implications for Capsule Depolymerase Treatment. Antimicrobial Agents and Chemotherapy, 59, 1038-1047. https://doi.org/10.1128/AAC.03560-14

[7] Vading, M., Nauclér, P., Kalin, M. and Giske, C.G. (2018) Invasive Infection Caused by Klebsiella pneumoniae Is a Disease Affecting Patients with High Comorbidity and Associated with High Long-Term Mortality. PLoS ONE, 13, e0195258. https://doi.org/10.1371/journal.pone.0195258

[8] Lee, C.-R., et al. (2017) Antimicrobial Resistance of Hypervirulent Klebsiella pneumoniae: Epidemiology, Hypervirulence-Associated Determinants, and Resistance Mechanisms. Frontiers in Cellular and Infection Microbiology, 7, 483. https://doi.org/10.3389/fcimb.2017.00483

[9] Rossi, B., et al. (2018) Hypervirulent Klebsiella pneumoniae in Cryptogenic Liver Abscesses, Paris, France. Emerging Infectious Diseases, 24, 221.

https://doi.org/10.3201/eid2402.170957

[10] Paczosa, M.K. and Mecsas, J. (2016) Klebsiella pneumoniae: Going on the Offense with a Strong Defense. Microbiology and Molecular Biology Reviews, 80, 629-661. https://doi.org/10.1128/MMBR.00078-15

[11] Pyra, A., et al. (2017) Tail Tubular Protein A: A Dual-Function Tail Protein of Klebsiella pneumoniae Bacteriophage KP32. Scientific Reports, 7, Article No. 2223. https://doi.org/10.1038/s41598-017-02451-3

[12] Harmer, C.J. and Hall, R.M. (2015) The A to Z of A/C Plasmids. Plasmid, 80, 63-82. https://doi.org/10.1016/j.plasmid.2015.04.003

[13] Rozwandowicz, M., et al. (2018) Plasmids Carrying Antimicrobial Resistance Genes in Enterobacteriaceae. Journal of Antimicrobial Chemotherapy, 73, 1121-1137. https://doi.org/10.1093/jac/dkx488

[14] Jacoby, G.A. (2017) Plasmid-Mediated Quinolone Resistance. In: Antimicrobial Drug Resistance, Springer, Berlin, 265-268. https://doi.org/10.1007/978-3-319-46718-4_17

[15] Margaritis, A., et al. (2017) Plasmid-Mediated Quinolone Resistance Determinants among Gram-Negative Bacteraemia Isolates: A Hidden Threat. Journal of Medical 
Microbiology, 66, 266-275. https://doi.org/10.1099/jmm.0.000397

[16] Cao, X., Xu, X., Zhang, Z., Shen, H., Chen, J. and Zhang, K. (2014) Molecular Characterization of Clinical Multidrug-Resistant Klebsiella pneumoniae Isolates. Annals of Clinical Microbiology and Antimicrobials, 13, Article No. 16. https://doi.org/10.1186/1476-0711-13-16

[17] Sotgiu, G., et al. (2018) Nosocomial Transmission of Carbapenem-Resistant Klebsiella pneumoniae in an Italian University Hospital: A Molecular Epidemiological Study. Journal of Hospital Infection, 99, 413-418. https://doi.org/10.1016/j.jhin.2018.03.033

[18] Iovleva, A. and Doi, Y. (2017) Carbapenem-Resistant Enterobacteriaceae. Clinics in Laboratory Medicine, 37, 303-315. https://doi.org/10.1016/j.cll.2017.01.005

[19] Zhang, R., Chan, E.W.-C., Zhou, H. and Chen, S. (2017) Prevalence and Genetic Characteristics of Carbapenem-Resistant Enterobacteriaceae Strains in China. The Lancet Infectious Diseases, 17, 256-257. https://doi.org/10.1016/S1473-3099(17)30072-5

[20] Snitkin, E.S., et al. (2017) Integrated Genomic and Interfacility Patient-Transfer Data Reveal the Transmission Pathways of Multidrug-Resistant Klebsiella pneumoniae in a Regional Outbreak. Science Translational Medicine, 9, eaan0093. https://doi.org/10.1126/scitranslmed.aan0093

[21] Friedman, N.D., Carmeli, Y., Walton, A.L. and Schwaber, M.J. (2017) Carbapenem-Resistant Enterobacteriaceae: A Strategic Roadmap for Infection Control. Infection Control \& Hospital Epidemiology, 38, 580-594. https://doi.org/10.1017/ice.2017.42

[22] Rodriguez, V., et al. (2015) A Multimodal Intervention to Improve Hand Hygiene in ICUs in Buenos Aires, Argentina: A Stepped Wedge Trial. International Journal for Quality in Health Care, 27, 405-411. https://doi.org/10.1093/intqhc/mzv065

[23] Grota, P.G. and Grant, P.S. (2018) Environmental Infection Prevention: Priorities of Patient Safety Collaboration. Critical Care Nursing Quarterly, 41, 38-46. https://doi.org/10.1097/CNQ.0000000000000184

[24] Sime, F.B., et al. (2017) Pharmacodynamics of Aerosolized Fosfomycin and Amikacin against Resistant Clinical Isolates of Pseudomonas aeruginosa and Klebsiella pneumoniae in a Hollow-Fiber Infection Model: Experimental Basis for Combination Therapy. Antimicrobial Agents and Chemotherapy, 61, e01763-16.

https://doi.org/10.1128/AAC.01763-16

[25] Kish and Leslie (1965).

[26] Acaku, M., et al. (2014) Prevalence and Genotypic Characterization of Extended-Spectrum Beta-Lactamases Produced by Gram Negative Bacilli at a Tertiary Care Hospital in Rural South Western Uganda. British Microbiology Research Journal, 4, 1541-1550. https://doi.org/10.9734/BMRJ/2014/9792

[27] Patel, J.B. (2017) Performance Standards for Antimicrobial Susceptibility Testing. Clinical and Laboratory Standards Institute.

[28] Bialvaei, A.Z., et al. (2016) Current Methods for the Identification of Carbapenemases. Journal of Chemotherapy, 28, 1-19. https://doi.org/10.1179/1973947815Y.0000000063

[29] Okoche, D., Asiimwe, B.B., Katabazi, F.A., Kato, L. and Najjuka, C.F. (2015) Prevalence and Characterization of Carbapenem-Resistant Enterobacteriaceae Isolated from Mulago National Referral Hospital, Uganda. PLOS ONE, 10, e0135745. https://doi.org/10.1371/journal.pone.0135745 
[30] Nagdeo, N.V., Kaore, N.M. and Thombare, V.R. (2012) Phenotypic Methods for Detection of Various $\beta$-Lactamases in Gram-Negative Clinical Isolates: Need of the Hour. Chronicles of Young Scientists, 3, 292. https://doi.org/10.4103/2229-5186.103098

[31] Mushi, M.F., Mshana, S.E., Imirzalioglu, C. and Bwanga, F. (2014) Carbapenemase Genes among Multidrug Resistant Gram Negative Clinical Isolates from a Tertiary Hospital in Mwanza, Tanzania. BioMed Research International, 2014, Article ID: 303104. https://doi.org/10.1155/2014/303104

[32] Shah, R.K., Ni, Z.H., Sun, X.Y., Wang, G.Q. and Li, F. (2017) The Determination and Correlation of Various Virulence Genes, ESBL, Serum Bactericidal Effect and Biofilm Formation of Clinical Isolated Classical Klebsiella pneumoniae and Hypervirulent Klebsiella pneumoniae from Respiratory Tract Infected Patients. Polish Journal of Microbiology, 66, 501-508. https://doi.org/10.5604/01.3001.0010.7042

[33] Nakaye, M., et al. (2014) AmpC-BETA Lactamases among Enterobacteriaceae Isolated at a Tertiary Hospital, South Western Uganda. British Biotechnology Journal, 4, 1026-1036. https://doi.org/10.9734/BBJ/2014/10570

[34] Mutiibwa, D. and Tumusiime, G. (2013) Aerobic Bacterial Causes of Secondary Peritonitis and Their Antibiotic Sensitivity Patterns among HIV Negative Patients with Non-Traumatic Small Bowel Perforations in Mbarara Regional Referral Hospital. East and Central African Journal of Surgery, 18, 34-39.

[35] Baguma, A., Kagirita, A. and Bazira, J. (2017) Prevalence of Extended-Spectrum Beta-Lactamases-Producing Microorganisms in Patients Admitted at KRRH, Southwestern Uganda. International Journal of Microbiology, 2017, Article ID: 3183076. https://doi.org/10.1155/2017/3183076

[36] George, M., et al. (2018) Bacterial Aetiology and Antibiotic Susceptibility Profile of Post-Operative Sepsis among Surgical Patients in a Tertiary Hospital in Rural Eastern Uganda. Microbiology Research Journal International, 24, MRJL.41690. https://doi.org/10.9734/MRJI/2018/41690

[37] Magufwa, A.F. (2016) Epidemiology of Urinary Tract Infection among Febrile Children under Five Years in Morogoro Municipality, Tanzania, Sokoine University of Agriculture.

[38] Nantanda, R., Hildenwall, H., Peterson, S., Kaddu-Mulindwa, D., Kalyesubula, I. and Tumwine, J.K. (2008) Bacterial Aetiology and Outcome in Children with Severe Pneumonia in Uganda. Annals of Tropical Paediatrics, 28, 253-260. https://doi.org/10.1179/146532808X375404

[39] Chakraborty, S., et al. (2016) Prevalence, Antibiotic Susceptibility Profiles and ESBL Production in Klebsiella pneumoniae and Klebsiella oxytoca among Hospitalized Patients. Periodicum Biologorum, 118, 53-58. https://doi.org/10.18054/pb.2016.118.1.3160

[40] Najjuka, C.F., Kateete, D.P., Kajumbula, H.M., Joloba, M.L. and Essack, S.Y. (2016) Antimicrobial Susceptibility Profiles of Escherichia coli and Klebsiella pneumoniae Isolated from Outpatients in Urban and Rural Districts of Uganda. BMC Research Notes, 9, 235. https://doi.org/10.1186/s13104-016-2049-8

[41] Mwaka, A., et al. (2011) Bacteriuria among Adult Non-Pregnant Women Attending Mulago Hospital Assessment Centre in Uganda. African Health Sciences, 11, 182-189.

[42] Stanley, I.J., et al. (2018) Multidrug Resistance among Escherichia coli and Klebsiella pneumoniae Carried in the Gut of Out-Patients from Pastoralist Communities of Kasese District, Uganda. PLoS ONE, 13, e0200093. 
https://doi.org/10.1371/journal.pone.0200093

[43] Odoki, M., et al. (2019) Prevalence of Bacterial Urinary Tract Infections and Associated Factors among Patients Attending Hospitals in Bushenyi District, Uganda. International Journal of Microbiology, 2019, Article ID: 4246780. https://doi.org/10.1155/2019/4246780

[44] Ampaire, L.M., et al. (2015) Epidemiology of Carbapenem Resistance among Multi-Drug Resistant Enterobacteriaceae in Uganda. British Microbiology Research Journal, 8, 418. https://doi.org/10.9734/BMRJ/2015/17055

[45] Kajumbula, H., et al. (2018) Antimicrobial Drug Resistance in Blood Culture Isolates at a Tertiary Hospital, Uganda. Emerging Infectious Diseases, 24, 174-175. https://doi.org/10.3201/eid2401.171112

[46] Kateregga, J.N., Kantume, R., Atuhaire, C., Lubowa, M.N. and Ndukui, J.G. (2015) Phenotypic Expression and Prevalence of ESBL-Producing Enterobacteriaceae in Samples Collected from Patients in Various Wards of Mulago Hospital, Uganda. BMC Pharmacology and Toxicology, 16, 14. https://doi.org/10.1186/s40360-015-0013-1

[47] Lubega, A., Joel, B. and Justina Lucy, N. (2017) Incidence and Etiology of Surgical Site Infections among Emergency Postoperative Patients in Mbarara Regional Referral Hospital, South Western Uganda. Surgery Research and Practice, 2017, Article ID: 6365172. https://doi.org/10.1155/2017/6365172

[48] Anderson, D.J., et al. (2008) Seasonal Variation in Klebsiella pneumoniae Bloodstream Infection on 4 Continents. The Journal of Infectious Diseases, 197, 752-756. https://doi.org/10.1086/527486

[49] Tang, J.W. (2009) The Effect of Environmental Parameters on the Survival of Airborne Infectious Agents. Journal of the Royal Society Interface, 6, S737-S746. https://doi.org/10.1098/rsif.2009.0227.focus

[50] Saidel-Odes, L., et al. (2012) A Randomized, Double-Blind, Placebo-Controlled Trial of Selective Digestive Decontamination Using Oral Gentamicin and Oral Polymyxin E for Eradication of Carbapenem-Resistant Klebsiella pneumoniae Carriage. Infection Control \& Hospital Epidemiology, 33, 14-19. https://doi.org/10.1086/663206

[51] Leski, T.A., et al. (2016) High Prevalence of Multidrug Resistant Enterobacteriaceae Isolated from Outpatient Urine Samples But Not the Hospital Environment in Bo, Sierra Leone. BMC Infectious Diseases, 16, 167. https://doi.org/10.1186/s12879-016-1495-1

[52] Ferreira, R.L., et al. (2018) High Prevalence of Multidrug-Resistant Klebsiella pneumoniae Harboring Several Virulence and $\beta$-Lactamase Encoding Genes in a Brazilian Intensive Care Unit. Frontiers in Microbiology, 9, 3198.

https://doi.org/10.3389/fmicb.2018.03198

[53] Eshetie, S., Unakal, C., Gelaw, A., Ayelign, B., Endris, M. and Moges, F. (2015) Multidrug Resistant and Carbapenemase Producing Enterobacteriaceae among Patients with Urinary Tract Infection at Referral Hospital, Northwest Ethiopia. Antimicrobial Resistance and Infection Control, 4, Article No. 12. https://doi.org/10.1186/s13756-015-0054-7

[54] Shatalov, A. (2015) Prevalence and Antibiotic Resistance Pattern of Escherichia coli and Klebsiella pneumoniae in Urine Tract Infections at the La Paz Medical Center, Malabo, Equatorial Guinea. Open Journal of Medical Microbiology, 5, 177. https://doi.org/10.4236/ojmm.2015.54022

[55] Sonda, T., et al. (2017) Meta-Analysis of Proportion Estimates of Extended-Spectrum- 
Beta-Lactamase-Producing Enterobacteriaceae in East Africa Hospitals. Antimicrobial Resistance \& Infection Control, 5, 18. https://doi.org/10.1186/s13756-016-0117-4

[56] Teklu, D.S., et al. (2019) Extended-Spectrum Beta-Lactamase Production and Multi-Drug Resistance among Enterobacteriaceae Isolated in Addis Ababa, Ethiopia. Antimicrobial Resistance \& Infection Control, 8, 39. https://doi.org/10.1186/s13756-019-0488-4

[57] Maina, D., Makau, P., Nyerere, A. and Revathi, G. (2013) Antimicrobial Resistance Patterns in Extended-Spectrum $\beta$-Lactamase Producing Escherichia coli and Klebsiella pneumoniae Isolates in a Private Tertiary Hospital, Kenya. Microbiology Discovery, 1, 5. https://doi.org/10.7243/2052-6180-1-5

[58] Seni, J., et al. (2013) Antimicrobial Resistance in Hospitalized Surgical Patients: A Silently Emerging Public Health Concern in Uganda. BMC Research Notes, 6, 298. https://doi.org/10.1186/1756-0500-6-298

[59] Desta, K., et al. (2016) High Gastrointestinal Colonization Rate with Extended-Spectrum $\beta$-Lactamase-Producing Enterobacteriaceae in Hospitalized $\mathrm{Pa}$ tients: Emergence of Carbapenemase-Producing K. Pneumoniae in Ethiopia. PLoS $O N E, 11$, e0161685. https://doi.org/10.1371/journal.pone.0161685

[60] Legese, M.H., Weldearegay, G.M. and Asrat, D. (2017) Extended-Spectrum Beta-Lactamase- and Carbapenemase-Producing Enterobacteriaceae among Ethiopian Children. Infection and Drug Resistance, 10, 27. https://doi.org/10.2147/IDR.S127177

[61] Medeiros, A.A. (1997) Evolution and Dissemination of $\beta$-Lactamases Accelerated by Generations of $\beta$-Lactam Antibiotics. Clinical Infectious Diseases, 24, S19-S45. https://doi.org/10.1093/clinids/24.Supplement_1.S19

[62] Maina, D., et al. (2012) Genotypes and Cephalosporin Susceptibility in Extended-Spectrum Beta-Lactamase Producing Enterobacteriaceae in the Community. The Journal of Infection in Developing Countries, 6, 470-477. https://doi.org/10.3855/jidc. 1456

[63] Ahmed, O.B., et al. (2013) Prevalence of TEM, SHV and CTX-M Genes in Escherichia coli and Klebsiella spp Urinary Isolates from Sudan with Confirmed ESBL Phenotype. Life Science Journal, 10, 191-195.

[64] Hara, G.L., et al. (2013) Detection, Treatment, and Prevention of Carbapenemase-Producing Enterobacteriaceae: Recommendations from an International Working Group. Journal of Chemotherapy, 25, 129-140. https://doi.org/10.1179/1973947812Y.0000000062

[65] EL-Ganiny, A.M., El-Mahdy, A.M., El-Latif, H.K.A., Ibrahem, R.H. and Abdelsabour, H.I. (2016) Phenotypic and Genotypic Detection of $\beta$-Lactams Resistance in Klebsiella Species from Egyptian Hospitals Revealed Carbapenem Resistance by OXA and NDM Genes. African Journal of Microbiology Research, 10, 339-347. https://doi.org/10.5897/AJMR2015.7871

[66] Saleh, M.M., et al. (2016) Detection of blaKPC and blaNDM Genes in Carbapenems Resistant Strains of Klebsiella pneumoniae Isolated from Some Egyptian Hospitals Patients. Suez Canal University Medical Journal, 19, 17-28.

[67] Bhaskar, M.M., Anand, R. and Harish, B. (2013) Prevalence of blaNDM-Producing Blood Isolates of Escherichia coli, Klebsiella Species and Enterobacter Species in a Tertiary Care Centre in South India. Journal of Microbiology Research and Reviews, 16, 61-68.

[68] Mohammed, Y., Zailani, S.B. and Onipede, A.O. (2015) Characterization of KPC, 
NDM and VIM Type Carbapenem Resistance Enterobacteriaceae from North Eastern, Nigeria. Journal of Biosciences and Medicines, 3, 100.

https://doi.org/10.4236/jbm.2015.311013

[69] Stuart, J.C. and Leverstein-Van Hall, M. (2010) Dutch Working Party on the Detection of Highly Resistant Microorganisms. Guideline for Phenotypic Screening and Confirmation of Carbapenemases in Enterobacteriaceae. International Journal of Antimicrobial Agents, 36, 205-210.

https://doi.org/10.1016/j.ijantimicag.2010.05.014

[70] Ogalo, E.A., et al. (2016) High Prevalence of Multi-Drug Resistant Klebsiella pneumoniae in a Tertiary Teaching Hospital in Western Kenya. African Journal of Infectious Diseases, 10, 89-95. https://doi.org/10.21010/ajid.v10i2.3

[71] Henson, S.P., et al. (2017) Molecular Epidemiology of Klebsiella pneumoniae Invasive Infections over a Decade at Kilifi County Hospital in Kenya. International Journal of Medical Microbiology, 307, 422-429.

https://doi.org/10.1016/j.ijmm.2017.07.006

[72] Poirel, L., Revathi, G., Bernabeu, S. and Nordmann, P. (2011) Detection of NDM-1Producing Klebsiella pneumoniae in Kenya. Antimicrobial Agents and Chemotherapy, 55, 934-936. https://doi.org/10.1128/AAC.01247-10

[73] Knothe, H., Shah, P., Krcmery, V., Antal, M. and Mitsuhashi, S. (1983) Transferable Resistance to Cefotaxime, Cefoxitin, Cefamandole and Cefuroxime in Clinical Isolates of Klebsiella pneumoniae and Serratia marcescens. Infection, 11, 315-317. https://doi.org/10.1007/BF01641355 